\title{
Efectos de LA EXPOSICIÓN A LOS MEdios DE COMUNICACIÓN Y LA DISCUSIÓN EN LAS ACTITUDES HACIA LA POLÍTICA ${ }^{1}$
}

\author{
Gerardo Maldonado ${ }^{2}$ \\ Mariano Torcal ${ }^{3}$
}

\begin{abstract}
Resumen: Teniendo en cuenta que la deliberación entre los ciudadanos y su interés en asuntos políticos son características ideales de una democracia moderna, en este trabajo se argumenta que la deliberación política puede tener algunos efectos negativos en actitudes de los ciudadanos hacia la política. Más preciso, esperamos establecer bajo qué condiciones la exposición a la información heterogénea de los medios de comunicación y la discusión entre intermediarios que están en desacuerdo deteriora el interés del ciudadano en política y la confianza política. Usando los datos del Proyecto Comparado de Elecciones Nacionales (CNEP) y, tras discutir algunas posiciones contradicciones de la literatura sobre este tema, va a mostrarse que, bajo ciertas circunstancias, estar expuesto a discusiones políticas en desacuerdo con las del propio entrevistado propicia un menor interés en la política, algo que no ocurre con la exposición a medios de información divergente. Sin embargo, esos
\end{abstract}

Queremos agradecer a Richard Gunther, director del proyecto CNEP, y a sus integrantes por el uso de los datos y por sus comentarios a diversas versiones de este trabajo. El mismo ha sido también posible por la financiación del Ministerio de Ciencia e Innovación de España, Plan Nacional de I+D+i, código CSO2009-14434 (2010-2013).

2 Candidato a Doctor en Ciencias Políticas y Sociales por la Universitat Pompeu Fabra de España. Es profesor investigador titular de la División de Estudios Internacionales del Centro de Investigación y Docencia Económicas (CIDE) en México, donde es además Coordinador de Metodología del proyecto de opinión pública y política exterior "Las Américas y el Mundo". gerardo.maldonado@cide.edu

3 Doctor en Ciencias Políticas por la Ohio State University y la Universidad Autónoma de Madrid. Es Catedrático de Ciencias Políticas en el Departamento de Ciencias Políticas y Sociales de la Universitat Pompeu Fabra en España. De 2001 a 2014 fue Coordinador Nacional de la Encuesta Social Europea en España. mariano.torcal@upf.edu 
efectos negativos están condicionados por el conocimiento político, por la fuerza de la identificación partidista a nivel individual y, a nivel contextual, por la polarización y fragmentación del sistema de partidos. Por último veremos que esto sólo afecta al interés pero no a la confianza política.

Palabras clave: interés en la política; eficacia política; medios de comunicación; discusión política; heterogeneidad de información política; polarización del sistema de partidos; fragmentación del sistema de partidos.

Abstract: Taking into account that political deliberation and political involvement are two ideal characteristics of any democracy, in this paper it is argued that deliberation can have some negative effects on citizens' attitudes toward politics. More concrete, we will establish under what conditions the exposition to heterogeneous information through mass media and interpersonal discussion decreases interest in politics and political efficacy. We use the Comparative National Elections Project (CNEP) data and, after discussing some contradictions in the academic literature about this topic, we demonstrate that, under certain circumstances, being exposed to disagreeing information with interpersonal discussants produces less interest in politics, something that does not occur with the exposition to disagreeing information through mass media. However, these negative effects are conditioned by political knowledge and partisanship strength at the individual level and, at the country level, by party system polarization and fragmentation. Finally, we discover that this only affects citizens' interest in politics, but neither internal nor external political efficacy.

Key words: political interest; political efficacy; mass media; political discussion; heterogeneous political information; party system polarization; party system fragmentation.

\section{Introducción}

El involucramiento político y la deliberación entre ciudadanos son características fundamentales de las democracias contemporáneas. En términos generales, la deliberación política deviene un mecanismo esencial para 
mejorar la calidad de las mismas, uniéndose al argumento sostenido por los defensores de la democracia deliberativa (Arendt, 1968; Habermas, 1984; Fishking, 1991; Elster, 1998; Fearon 1998). Esta idea no es nueva -ya acuñada desde Aristóteles, Tocqueville, Stuart Mill hasta los teóricos políticos contemporáneos- y está basada en que la deliberación política contribuye a una mejor formación de posiciones individuales en asuntos públicos e inculca interés y eficiencia políticas entre la ciudadanía (Almond y Verba, 1963). Esto ocurre al permitir que los ciudadanos reconozcan la variedad de argumentos alrededor de la política y al incrementar su preocupación por la necesidad de formarse opiniones más consistentes que, una vez formadas, ayuden a impulsar sus intereses y preferencias (Bächtinger y Pedrini, 2010; Delli Carpini y Keeter, 1989; Delli Carpini, et al., 2004; Fishkin, 1997; Mutz, 2006).

No obstante lo anterior, la extensa atención académica a este fenómeno no ha sido del todo concluyente, pues ha señalado efectos tanto positivos como negativos, en especial cuando se distinguen entre distintas formas de deliberación política. La deliberación en democracias contemporáneas ocurre, la mayor parte del tiempo, mediante dos mecanismos importantes de intermediación: la discusión entre ciudadanos y la exposición a la información de los medios de comunicación. La discusión política puede producir una ciudadanía más informada y comprometida (Eveland y Thomson, 2006; Eveland y Hively, 2009) y conduce a mayores niveles de participación política (Verba, Scholzman y Brady, 1995; Lake y Huckfeldt, 1998; Mutz, 2002a; Sheufele, Nisbet, Brossard y Nisbet, 2004; SchmittBeck y Mackenrodt, 2010). Esta influencia positiva ha sido señalada tanto si se habla de la cantidad de interlocutores personales a los que el ciudadano está expuesto, como para la presencia de distintos puntos de vista políticos entre 
estos interlocutores (Huckfeldt, Mendez y Osborn, 2004; Mutz, 2002a; Nir, 2005; Moy y Gastil, 2006).

Lo mismo puede decirse de la exposición de los ciudadanos a la información política en los medios de comunicación, ya que también se ha argumentado que incrementa su conciencia política (awareness) y los hace más informados y activos (Zaller, 1992; Prior 2007; Mutz y Martin 2001). En el mismo sentido, para algunos, la exposición a medios de comunicación crea "mejores ciudadanos" al aumentar el involucramiento político y las actitudes cívicas (Newton 1999; Norris 2000; Luskin y Fishkin 2002; Searing et al., 2007).

A pesar de estas consecuencias positivas y deseables, la deliberación política puede también tener resultados negativos para la democracia, especialmente en situaciones de alta confrontación y polarización, mediante el aumento del escepticismo y el desinterés político (Berelson, et al., 1954; Campbell, et al., 1960). Algunos académicos argumentan que la mera experiencia con el desacuerdo en la vida diaria, incluyendo las discusiones políticas con aquéllos cuyas preferencias políticas son diferentes, puede promover la apatía y la desvinculación políticas (Mutz, 2002a). Otros sostienen que el sesgo antipolítico en la información de los medios de comunicación es la causa principal de la disminución del compromiso civil, del capital social y de la confianza política (Putnam, 1993 y 2000; Zaller, 1996; Avery, 2009).

¿Cuál es entonces el efecto preciso de estos mecanismos de deliberación política en las actitudes democráticas de los ciudadanos? ¿Qué tan positiva o negativa puede ser para los sentimientos ciudadanos la exposición a diferentes puntos de vista a través de estos intermediarios políticos? ¿El efecto de la exposición a los medios de comunicación es igual al de la discusión interpersonal? Además, ¿los efectos 
dependen del nivel de polarización o fragmentación del sistema de partidos en un país?

Este trabajo trata de responder estas preguntas al estimar los efectos de la pluralidad y heterogeneidad de la exposición a los medios de comunicación y conversaciones políticas en tres actitudes democráticas básicas: el interés en la política y las eficacias políticas, tanto la interna como la externa. Estas actitudes configuran dos dimensiones básicas de la desafección política: desafección institucional y desapego político (Torcal y Montero, 2006; Gunther, Montero y Torcal, 2007).

Para responder estas cuestiones sobre los efectos de la deliberación política en las actitudes, también debemos explorar las posibles condiciones que propicien las consecuencias positivas y negativas de la intermediación política. Éstas pueden estar relacionadas con factores específicos a los individuos o con aquéllos externos a los mismos y que forman parte del contexto político (Huckfeldt, Ikeda y Pappi, 2005: 498-500; Schmitt-Beck y Voltmer, 2007). Hay factores individuales, especialmente el grado de conocimiento político y la fuerza de las identidades partidistas, que podrían condicionar los efectos de la deliberación en las actitudes democráticas de los ciudadanos. De entre los elementos contextuales, el efecto de la intermediación puede depender del grado de heterogeneidad y confrontación entre los principales partidos nacionales, haciendo que la deliberación política sea más difícil y con más costes emocionales. Esto es, en un contexto de mayor polarización y fragmentación, la exposición política discordante puede hacer a las personas más inciertas de su propia posición y producir alguna desmovilización (Mutz, 2002a: 840), aumentando también el coste personal de la confrontación (Mutz y Martin, 2001).

Se abordarán estas cuestiones utilizando los datos del Proyecto Comparado de Elecciones Nacionales (CNEP, por 
sus siglas en inglés). Primero, van a mostrarse las diferencias nacionales de las actitudes de desafección política y de los mecanismos de intermediación. Después, se estimará si esta intermediación política tiene efectos, positivos o negativos, en las actitudes políticas. Finalmente, se tratará de evaluar si estos efectos son uniformes entre distintos tipos de individuos y entre países, o si están condicionados por el conocimiento político y la identificación partidista a nivel individual, y por la polarización o fragmentación de sus respectivos sistemas de partidos a nivel agregado.

\section{Desafección política, discusión política y comunicación en medios de comunicación}

¿Por qué la eficacia y el interés políticos son importantes? En términos teóricos (Almond y Verba, 1963; Van Deth, 1990; Denters et al., 2007), un buen ciudadano puede ser caracterizado -además de a través de ciertos valores, normas, derechos y deberes- como un individuo interesado e involucrado en la política y los asuntos públicos. También se espera que la participación pública de este ciudadano esté basada en un mínimo de aceptación y confianza en las instituciones representativas y que tenga suficientes conocimientos para evaluar su desempeño. Los altos niveles actuales de apatía política sugieren lo opuesto al buen ciudadano ideal, ya que los sentimientos apáticos implican que los individuos se abstienen de la vida política y se ven como ineficaces políticamente y perciben al sistema político como irresponsable (Torcal y Montero, 2006).

¿Por qué, en este marco, es necesario estudiar los intermediarios políticos? Los efectos de los mecanismos de intermediación en las normas y en las actitudes de los ciudadanos es un tema especialmente importante en democracias contemporáneas pues, por un lado, los vínculos 
partidistas y las identificaciones políticas han ido decayendo en importancia en las sociedades actuales, mientras que, por el otro, la influencia de la información de los medios de comunicación en las actitudes de los ciudadanos y en su comportamiento se ha ido incrementando (Dalton, 2004; Huckfeldt Johnson y Sprague, 2004; Ikeda y Huckfeldt, 2001; Magalhâes, 2007; Morales, 2010).

¿Por qué hasta ahora la literatura ha sido insatisfactoria o no concluyente respecto a los efectos de la intermediación política en las actitudes de desafección? En primer lugar, la literatura dedicada a estudiar los efectos en actitudes políticas -con pocas excepciones (Searing et al., 2007)- se ha enfocado, mayoritariamente, en los medios de comunicación (ver Norris, 1999, 2000 y 2011; Putnam, 2000). Otros análisis, salvo contadas excepciones (Huckfeldt, Ikeda y Pappi, 2005; Strömbäck y Shehata, 2010; Toka, 2010), se han centrado más en el efecto de estos intermediarios en la tolerancia y moderación políticas (Mutz, 1998; Mutz y Mondak, 2006) o en la participación política (Mutz, 2002a), generalmente ignorando el efecto que la misma pueda tener en actitudes hacia la democracia (para alguna excepción, véase Schmitt-Beck y Voltmer, 2007). Segundo, incluso los trabajos que tienen las actitudes políticas como variable dependiente han estado centrados, principalmente, en el efecto de la frecuencia o pluralidad del uso de los intermediarios políticos, sin analizar el posible efecto de la exposición a la información heterogénea (para excepciones, ver Mutz, 2002b; Huckfeldt, Ikeda y Pappi, 2005; Eveland y Hively, 2009; Goldman y Mutz, 2011). Finalmente, y aun más importante, los análisis del fenómeno de desafección no han considerado el efecto negativo que la discusión política y la exposición a los medios de comunicación pueden tener al aumentar el sesgo partidista en la información y propiciar una mayor segmentación de opiniones políticas 
y una mayor confrontación política (especialmente en sistemas de partidos altamente fragmentados).

¿Cuál es entonces la relación previsible entre las actitudes de desafección política y los mecanismos de deliberación política? En primer lugar, es posible esperar que la simple frecuencia o pluralidad de exposición a intermediarios políticos, tanto medios de comunicación como discusiones informales sobre política, sea distinta a la exposición a información heterogénea a través de estos intermediarios. Se sabe que existe una tendencia humana a seleccionar interlocutores que son similares políticamente (Huckfeldt y Sprague, 1995) y a escoger contenidos afines en los medios de comunicación (Lazarsfeld et al., 1944; Katz, 1981); así el intercambio de información es típicamente la búsqueda de una experiencia placentera, de entretenimiento y tranquilizadora (Rosenberg, 2007). Sin embargo, no todo el intercambio de información ocurre en situaciones de homogeneidad o de ideas afines. De hecho, y más importante, la deliberación política requiere de intercambios de información con ciudadanos que no tienen las mismas ideas o preferencias políticas (Mutz, 2006).

Los intercambios de información con personas que tienen puntos de vista diferentes o el enfrentarse a noticias en desacuerdo con uno pueden tener un efecto nocivo que resulte en una experiencia desagradable que inhiba el interés político o que incremente el sentimiento de eficacia política y la inacción. Por lo tanto, la heterogeneidad o exposición transversal (cross-cutting) de información podría no sólo ser una experiencia más incómoda para los ciudadanos, sino también incrementar la incertidumbre de su posición sobre temas y candidatos, y así éstos estarían menos propensos a tomar acciones políticas y a sentirse más confundidos y menos capaces para entender la política, lo que les haría perder el interés y percibir el sistema como insensible a sus demandas (Berelson, Lazarsfeld y 
Mc Phee, 1954). La información heterogénea, y su conflicto inherente, puede producir una devaluación de la política (Mutz 2002a). ${ }^{4}$

Ahora bien, la exposición a los medios de comunicación y las discusiones interpersonales pueden tener también distintos efectos en las actitudes políticas debido a las diferencias intrínsecas entre estos dos intermediarios. Los medios de comunicación masivos por definición producen una exposición mayor a información política heterogénea que la discusión interpersonal (Bartels, 1993; Mutz y Martin, 2001), aunque las discusiones heterogéneas pueden implicar un costo individual mayor en el intercambio de información. Entonces, es posible esperar que la discusión interpersonal heterogénea tenga efectos negativos en el involucramiento político y que los medios de comunicación produzcan efectos positivos. Ésta no es un conjetura sobre si la relación entre la información de los medios de comunicación y la discusión interpersonal en la formación de la opinión de los ciudadanos es competitiva, independiente o complementaria (para una discusión reciente de estos dos efectos ver Beck et al., 2002; Schmitt-Beck, 2003; Marquis, 2010). Nuestro argumento pretende valorar si los efectos de la heterogeneidad en medios de comunicación masivos son diferentes a los de la comunicación interpersonal en el mismo conjunto de actitudes ciudadanas.

Igualmente, como se mostrará en este artículo, los efectos de los medios de comunicación y las conversaciones políticas pueden estar condicionados por el nivel del conocimiento político individual. Los ciudadanos con mayor conocimiento tienen más información fáctica y un

Se sabe, además, que la heterogeneidad de información política puede disminuir la participación política (Mutz, 2002a), al menos en términos convencionales, aunque la exposición heterogénea puede ser un factor de movilización de otros tipos de participación (ver Ulbig y Funk 1999; Lup, 2010). 
conjunto más estructurado de opiniones para lidiar con atajos contradictorios, lo que los ayuda a tomar decisiones más racionales y consistentes (Delli Carpini y Keeter 1989; Zaller 1992). Así, ciudadanos con más conocimientos o sofisticación política pueden tener menos intercambios de información incómoda, pues el desacuerdo les cuesta menos esfuerzo cognitivo. En el sentido opuesto, es posible esperar entonces que en aquellos individuos con un nivel bajo de conocimientos políticos se presente más claramente el efecto negativo de la deliberación política, pues tienen menos recursos cognitivos para enfrentar la información en desacuerdo o conflictiva.

Las consecuencias negativas de las discusiones en las actitudes políticas también pueden estar condicionadas a nivel individual por la intensidad de las identidades personales (sociales y políticas) que enmarcan los conflictos. ${ }^{5}$ En esta lógica, la siguiente expectativa es que la exposición heterogénea tenga un impacto mayor entre partidistas fuertes. La conversación con individuos que tienen diferentes puntos de vista puede tener un impacto mayor en ciudadanos con una fuerte identificación partidaria, pues tienen que lidiar especialmente con el malestar del desacuerdo. Esto puede incrementar la falta de confianza en instituciones de representación o el interés en la esfera política.

Finalmente, se pretende comprobar si la influencia de la intermediación en tales actitudes puede reflejar o no la

Como Carling y Love (2013) han mostrado, el partidismo condiciona la confianza social general: los individuos tienden a desconfiar más en aquéllos que se identifican con partidos políticos diferentes al propio. Richardson y Beck (2007), similarmente, han mostrado que el partidismo tiene una influencia en el flujo de información en la mayoría de los ciudadanos y que los partidistas fuertes están menos expuestos a diferentes opiniones políticas (Mutz y Martin, 2001: 108-109; Huckfeldt, Ikeda y Pappi, 2005: 504-505). 
confrontación y fragmentación políticas, con implicaciones para los efectos individuales y agregados de la intermediación. La polarización y fragmentación del sistema de partidos puede afectar el tamaño de los grupos políticos y la distancia ideológica entre ellos. Esto tiene un sustento directo en las oportunidades de exposición a información heterogénea, con un riesgo adicional de transformar el intercambio interpersonal en una experiencia desagradable (Mutz y Martin, 2001). En un contexto de fragmentación y polarización, los ciudadanos pueden tener mayor probabilidad de seleccionar interlocutores (Huckfeldt, Ikeda y Pappi, 2005: 499) o medios de comunicación (Goldmand y Mutz, 2011) con las mismas opiniones políticas, lo que reduce la posibilidad de una exposición heterogénea. Al mismo tiempo, esto puede aumentar el impacto negativo de este tipo de información política, al hacer a los ciudadanos más incómodos frente a esa exposición heterogénea y entonces incrementar su alejamiento y desentendimiento de la política.

Entre los distintos elementos contextuales que pueden afectar el efecto de la heterogeneidad en la exposición a discusiones interpersonales puede resaltarse la importancia del tamaño de los grupos, medida por la fragmentación del conflicto (fragmentación del sistema de partidos), y el nivel de encapsulación del conflicto, medido por la polarización política y la segmentación de esos grupos (Huckfeldt, Ikeda y Pappi, 2005: 499). Ambos elementos pueden tener un impacto claro en el nivel de exposición y en el intercambio de información en desacuerdo, y ambos están, como se acaba de señalar, relacionados con dos características básicas del sistema de partidos: su fragmentación y su polarización. 


\section{Mediciones de interés en la política y eficacia política interna y externa}

Antes de proceder al análisis, deben discutirse algunos de los conceptos claves y su operacionalización. El "interés político", o involucramiento psicológico en política, significa simplemente "el grado al que la política despierta la curiosidad del ciudadano" (Campbell, Gurin y Miller, 1954: 33). Esta definición minimalista no incluye las posibles consecuencias motivacionales o actitudinales, ya que "intereses e involucramiento psicológico pueden existir sin producir ninguna determinada manifestación externa" (van Deth, 1990: 279). No obstante, el interés en la política es una variable importante ya que puede ser que muchos ciudadanos estén interesados en política aunque sean simplemente espectadores. Aun así, hay una relación cercana entre el interés en la política y la conciencia y capacidad política individual: las personas no pueden ser curiosas acerca de las cosas que no perciben. La misma lógica se aplica a las habilidades y al conocimiento políticos (van Deth, 1990). El interés político es equivalente a poner atención, es "un prerrequisito para aprender cualquier cosa que pueda dar al ciudadano la oportunidad de participar en la toma de decisiones democráticas" (Lupia y McCubbins, 1998: 22). Así que el interés político es el mejor indicador de la existencia de preocupación, competencia, información y conocimiento acerca de la política. La consistencia y persistencia de las opiniones políticas de los ciudadanos en el tiempo depende del nivel del interés político y de su persistencia en el tiempo (Lupia y McCubbins, 1998: 289-297).

La "eficacia política" puede ser definida como el grado en que los ciudadanos se sienten calificados para enfrentarse a los asuntos políticos. Se trata, por tanto, de un sentimiento que los orienta hacia el mundo político y 
los provee de confianza en sí mismos para participar en él (Almond y Verba, 1963). Esta actitud fue inicialmente medida por cinco indicadores (Campbell, Gurin y Miller, 1954: 187-188), después se redujeron a cuatro: dos para la eficacia interna y dos para la eficacia externa (Niemi, Craige y Mattei, 1991). A pesar del intenso debate acerca de la validez de estos cuatro indicadores, actualmente la eficacia política interna es generalmente medida por el acuerdo o desacuerdo con la siguiente afirmación: "Por lo general, la política parece tan complicada que la gente como yo no entiende lo que sucede". En cambio, la eficacia política externa es el sentimiento o la percepción acerca de la receptividad (responsiveness) de los representantes políticos y del sistema democrático a las demandas de los ciudadanos. Normalmente, esta actitud es medida por el grado de acuerdo o desacuerdo con la siguiente frase: "Los políticos no se preocupan mucho de lo que piensa la gente como yo".

En este artículo se utilizan los datos del Comparative National Elections Project (CNEP). El CNEP reúne datos individuales de encuestas representativas a nivel estatal en diversos países y de elecciones que contienen información sobre los mecanismos de intermediación a través de los cuales los ciudadanos reciben información sobre políticas públicas, partidos políticos, candidatos y política en general durante el tiempo de campaña electoral. ${ }^{6}$ Igualmente, el CNEP ha recolectado información sobre las actitudes

La finalidad teórica del CNEP es revivir la perspectiva de investigación de la Escuela de Columbia establecida por Paul Lazarsfeld y sus colegas: el contexto social del comportamiento electoral. Los cuestionarios de la encuesta incluyen baterías de preguntas sobre los flujos de información durante la campaña electoral a través de tres ámbitos: las redes personales de discusión, los medios de comunicación y las asociaciones $\mathrm{u}$ organizaciones secundarias. El CNEP reúne información sobre elecciones nacionales en más de veinte diferentes sistemas políticos de cuatro continentes. La información sobre las características del proyecto, sus 
políticas de los ciudadanos entrevistados por lo que nos permite estimar su relación con los intermediarios políticos.

Entre los encuestados por el CNEP, a la pregunta por estar "muy" o "algo" interesados en la política, las respuestas positivas fueron desde el $19 \%$ de la población (en Chile en 1993) hasta el $78 \%$ de la población (en Estados Unidos en 2004) (ver Figura 1). En sólo tres países más del 50\% de los encuestados dijeron que estaban interesados en política: Portugal en 2005, Mozambique en 2005 y Estados Unidos.

Este ranking no revela patrones relativos a la edad de la democracia, ni a la distribución del ingreso ni a la riqueza. Tampoco indica nada respecto de una tendencia clara a lo largo del tiempo. En este sentido, es relevante mencionar que en los países donde los datos fueron recogidos en dos elecciones distintas, el porcentaje de los ciudadanos interesados incrementa durante el tiempo. La porción de los ciudadanos interesados en España creció del 25\% en 1993 al 37\% en 2004; en Hungría, del 30\% en 1998 al 44\% en 2006; y en Uruguay, del 38\% en 1994 al 42\% diez años después.

La historia es similar en el caso de la eficacia política interna y externa (véanse las figuras 2 y 3 ). Estados Unidos tiene el porcentaje más alto de ciudadanos en desacuerdo con la afirmación de que la política es muy complicada para las personas como ellos (65\% en 2004), mientras que Taiwán tiene el porcentaje más bajo $(20 \%$, también en 2004). Donde los datos del país estaban disponibles para dos elecciones o medidas en el tiempo, la proporción de ciudadanos con sentimiento de eficacia política interna parece ser más alta en la elección más reciente; esto ocurre de manera notable en Uruguay, pues el aumento fue del $40 \%$ en 1994 al $60 \%$ en 2004.

fases, así como una liga a las bases de datos públicas se encuentra en http://mershoncenter.osu.edu/expertise/institutions/cnep.htm 
En términos de eficacia política externa, el desacuerdo con la declaración de que a los políticos no les importa qué piensan los ciudadanos va del $11 \%$ de la población de Bulgaria en 1996 al 44\% de la población de Estados Unidos en 2004. Uruguay es, de nuevo, particularmente interesante: entre 1994 y 2004, la proporción de los ciudadanos eficaces aumentó casi 20 puntos. A pesar de las muchas diferencias entre países, éstas no parecen mostrar tampoco patrones claros que explican tales diferencias.

Aun así, estas tres actitudes tienden a estar muy relacionadas. La distribución agregada entre países de estas actitudes es muy similar. Primero, las eficacias interna y externa muestran una correlación de Pearson de 0,60; luego, la correlación entre eficacia interna e interés político es casi tan alta $(0,59)$ y, finalmente, la correlación entre eficacia externa e interés político es la más baja $(0,40)$, pero aun así significativa. Esta correlación en el ámbito agregado está también presente a nivel individual, con valores de correlación de 0,32, 0,25 y 0,14, respectivamente. Por tanto, es posible afirmar que estas actitudes están suficientemente interconectadas para constituir un indicador general de la desafección política general. No obstante, es importante estudiarlas de manera separada, pues reflejan cada una de las dimensiones diferentes de la desafección política (Torcal y Montero, 2006; Gunther, Montero y Torcal, 2007) y podrían ser afectadas por los distintos mecanismos de intermediación política de manera diversa. 

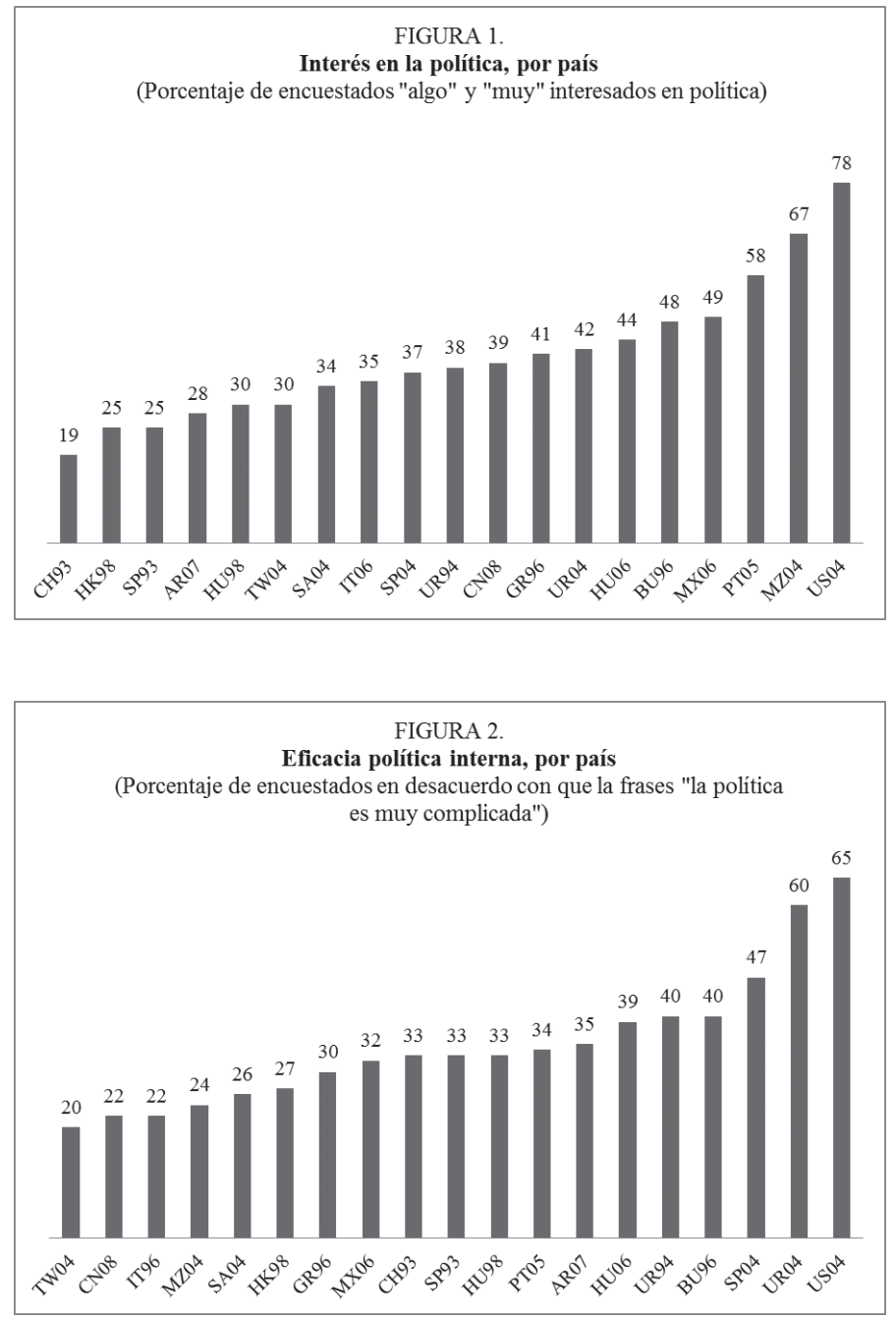


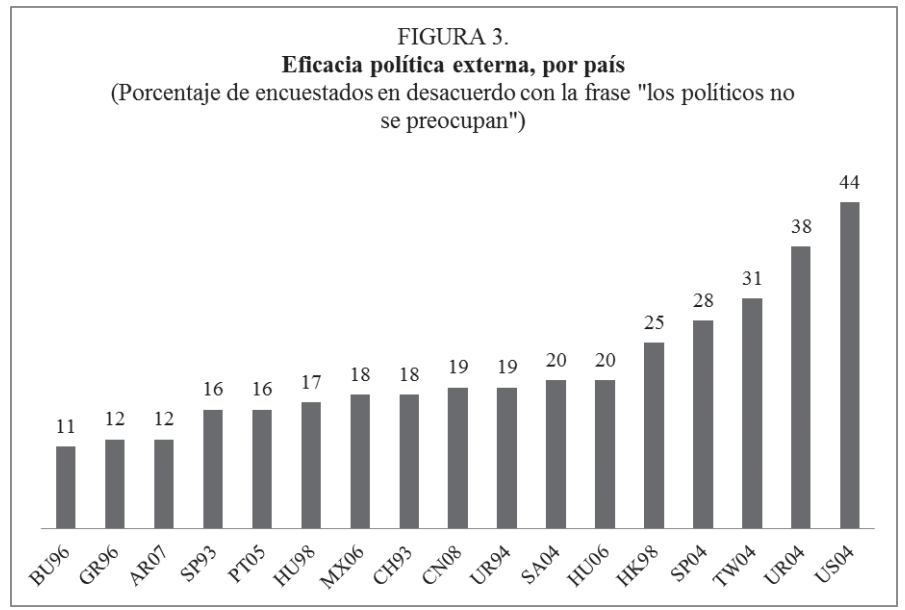

\section{Pluralidad y heterogeneidad de la intermediación política}

Para analizar los diferentes componentes del proceso de intermediación política, se han creado dos diferentes variables a partir de los datos de la encuesta CNEP para cada uno de los intermediarios: el número de intermediarios (o la "pluralidad") y el grado de desacuerdo (o "heterogeneidad") en la información recibida a través de la exposición a los medios masivos de comunicación y a la conversación política interpersonal.

"Pluralidad de los medios masivos de comunicación" significa la cantidad de canales de información a la cual los individuos se expusieron durante la campaña electoral. Nuestra medida procede de la pregunta del cuestionario de CNEP sobre cuántos días a la semana en promedio el encuestado utilizó diferentes medios de comunicación 
durante la campaña electoral. La encuesta CNEP provee información acerca del uso de tres medios de comunicación masivos: periódicos, radio y televisión; y a todos los encuestados se les pidió que mencionaran hasta dos tipos o fuentes distintas para cada uno de estos tres medios de comunicación.

Utilizando esta información, creamos una variable binaria para cada intermediario de medios de comunicación: codificamos 1 si el encuestado declaró usar el intermediario al menos una vez a la semana y 0 si no. Después creamos una variable que suma la cantidad de medios de comunicación usados durante la campaña con un rango de 0 a 6 (para máximo de dos cadenas de televisión, dos estaciones de radio y dos periódicos).

La "heterogeneidad de la exposición a los medios de comunicación" es entendida aquí como el grado de exposición a información política vía medios de comunicación que el entrevistado recibe y que tienen preferencias partidistas o ideológicas distintas a las de los encuestados. Para medirla, usamos las preguntas sobre las percepciones del entrevistado respecto del sesgo que creían que cada periódico que leían tenían hacia un partido o candidato. Lo mismo se hizo para radio y televisión. Después, se crearon variables dicótomas para cada periódico, radio o televisión a los que estuvieron expuestos al darle una puntuación de 1 donde el sesgo partidario del medio era evaluado como distinto a las preferencias individuales políticas (el claro desacuerdo) y 0 al contrario (indicando que había acuerdo respecto al sesgo o que el encuestado declaraba que el medio carecía de dicho sesgo).

Finalmente, se ha creado una variable que suma el número de medios masivos de comunicación que están en desacuerdo con las preferencias políticas del entrevistado. Esta nueva variable incluye como opciones: 0 (que indica el acuerdo con cualquier intermediario), 1 (donde 
el ciudadano estuvo expuesto según su opinión a al menos un intermediario en desacuerdo partidario), 2 (cuando el ciudadano clasificó a dos intermediarios con un sesgo partidario distinto al suyo) y así sucesivamente hasta un máximo de 6. En otras palabras, se está midiendo el nivel de "desacuerdo" o de heterogeneidad respecto de la información recibida por los medios de comunicación -aquello que Mutz (2002b) ha denominado como exposición cruzada o transversal (cross-cutting)-. ${ }^{7}$

Dos casos hipotéticos servirán para ejemplificar la operacionalización de los conceptos de pluralidad y de heterogeneidad de la intermediación política. Para la elección presidencial de 2004 en Estados Unidos, un individuo podía reportar haber visto dos cadenas de televisión (Fox y CNN), haber leído un periódico diario (The New York Times) y haber escuchado una vez a la semana una estación de radio. En nuestra medida de pluralidad, este individuo recibe un puntuación de 4 . Pero si esa persona afirma que sólo la información de Fox News es distinta a su preferencia de voto, su puntuación de heterogeneidad es de 1.

En contraste, para la elección general de 1993 en España, un individuo que reportaba haber visto a diario la transmisión de noticias de Televisión Española (TVE-1), haber leído el periódico El Mundo una vez a la semana y haber escuchado la estación de radio COPE una vez a la semana, también podría obtener un 3 en la variable pluralidad, pero tendría un valor de 2 en nuestra medida de heterogeneidad de los intermediarios de los medios de comunicación, si declarase que la información de El Mundo y COPE difieren con respecto a su preferencia de voto.

Otra medida de heterogeneidad estima el total de la diversidad ideológica o partidaria de los medios de comunicación a los que están expuestos los ciudadanos, pero estamos más interesados aquí en el efecto neto de la exposición a información en desacuerdo en vez de la diversidad entre los medios de comunicación a los cuales está expuesto un individuo. 
Para la "pluralidad de la discusión política", se ha usado la pregunta de la encuesta CNEP que contenía información sobre la frecuencia con que el encuestado hablaba sobre política con tres posibles intermediarios: la pareja, un primer interlocutor y un segundo interlocutor. Para cada uno de ellos se construyó una variable dicotómica: se le asignó el valor 1 si habían hablado al menos una vez a la semana durante la campaña electoral y 0 si no hubo ninguna conversación. Después sumamos estas variables para obtener un indicador agregado del número de intermediarios personales, con valores entre 0 y 3 . De igual manera se obtuvo una medida del grado de "heterogeneidad en discusión política" al establecer, primero, para cada interlocutor una variable donde 0 implica que no hubo diferencias en las preferencias políticas con el individuo y 1 significa haber estado en desacuerdo. Estas variables se sumaron para construir una escala que medía el número de interlocutores personales en desacuerdo, lo que resulta en una variable que va de 0 a 3.

A modo de ejemplo se presentan ahora dos situaciones hipotéticas sobre conversaciones políticas para mostrar cómo operacionalizar estos conceptos utilizando el caso de las elecciones presidenciales de México en 2006. Tomemos dos ejemplos: por un lado, un individuo que declaró haber hablado regularmente sobre política con su pareja, su padre (como su primer interlocutor) y su hermana (su segundo interlocutor) y que afirmó que los tres compartían preferencias partidarias; por otro lado, un entrevistado que afirmó que durante la campaña discutió sobre política únicamente con un amigo, pero que ese amigo votó por el Partido Revolucionario Institucional (PRI) mientras que él votó por el Partido Acción Nacional (PAN). En el primer caso, el individuo recibiría una puntuación de 3 en nuestra medida de pluralidad y 0 en la de heterogeneidad; y en el segundo, el entrevistado obtendría un 1 tanto para la 
variable que mide la pluralidad como para la que mide la heterogeneidad.

La figura 4 muestra el porcentaje por país y por año de los individuos expuestos a los medios masivos de comunicación para veinte elecciones en dieciséis países, y con datos para dos elecciones de Grecia (en 1996 y 2004), Hungría (1998 y 2006), España (1993 y 2004) y Uruguay (1994 y 2004). Como se muestra en esta figura, la mayoría de los ciudadanos en todos los países estuvieron expuestos al menos a un medio masivo de comunicación, aunque hay diferencias importantes entre países. Hay tres países con niveles bajos de exposición a los medios (pluralidad): Chile con un $40 \%$ de encuestados que declararon que no estuvieron expuestos a medio informativo alguno, seguido por México donde el 36\% afirmó lo mismo y, por último, Uruguay con un escaso 33\% para su elección de 1994. En el otro extremo, sólo el 4\% en Italia, en Grecia y en Hong Kong y el 1\% en Estados Unidos dijeron no tener exposición alguna a cualquier medio masivo de comunicación. Los países con información disponible para dos elecciones (Grecia, Hungría, España y Estados Unidos) muestran cierta estabilidad en este comportamiento en el tiempo. La excepción fue Uruguay, que mostró un aumento claro y significativo en su pluralidad de exposición entre 1994 y 2004. Adicionalmente, ningún patrón específico emerge de la distribución entre países de estas variables, habiendo incluso nuevas y viejas democracias en cada lado del espectro respecto a la intermediación política. 


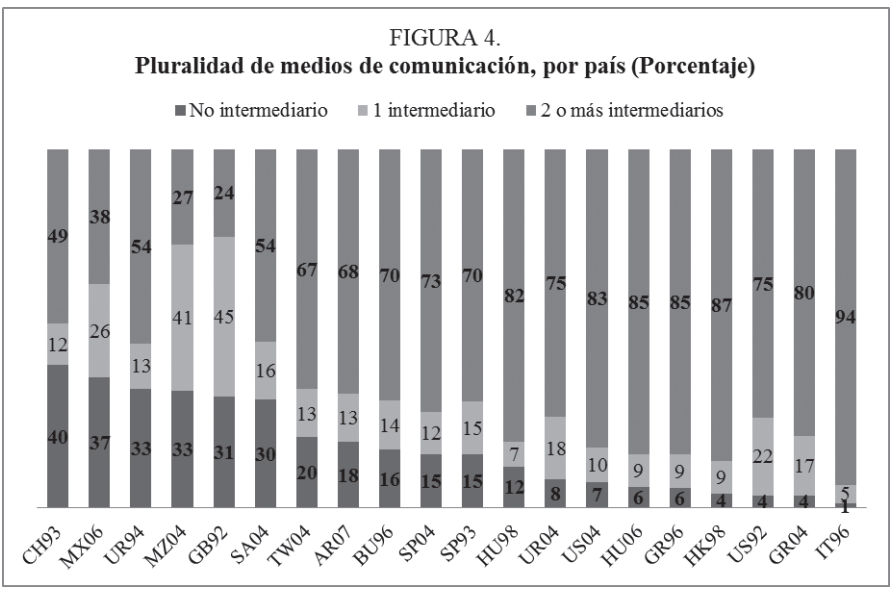

La figura 5 muestra el porcentaje de ciudadanos por país y año expuestos a cero, uno o más de un interlocutor político para veintitrés elecciones nacionales en diecisiete países, con datos para dos elecciones en Grecia, Hungría, España, Uruguay y Estados Unidos. En general, y comparando con los datos anteriores, se observa que la exposición a los medios de comunicación produce una mayor exposición plural a la información que la discusión interpersonal; esto es, los medios parecen ser más importantes para transmitir información al electorado que la discusión interpersonal en todos los países.

Sin embargo, hay variaciones importantes entre países, con niveles muy altos de discusión en Hong Kong (53,7\%), en Chile (47,2\% en 1993 y 51,4\% en 2000) y en Uruguay (51,2\% en 1994). En el otro extremo y con muy escasos niveles de discusión interpersonal están Italia (6,5\%), Estados Unidos (7\% en 1992 y 8,1\% en 2004) y Mozambique (10,7\%). De nuevo, se observa estabilidad en los países donde fue posible dos mediciones en el tiempo -con la excepción de Uruguay-. Además, la distribución de los dos indicadores 
de pluralidad de medios y conversaciones políticas por países parece ser similar. ${ }^{8}$

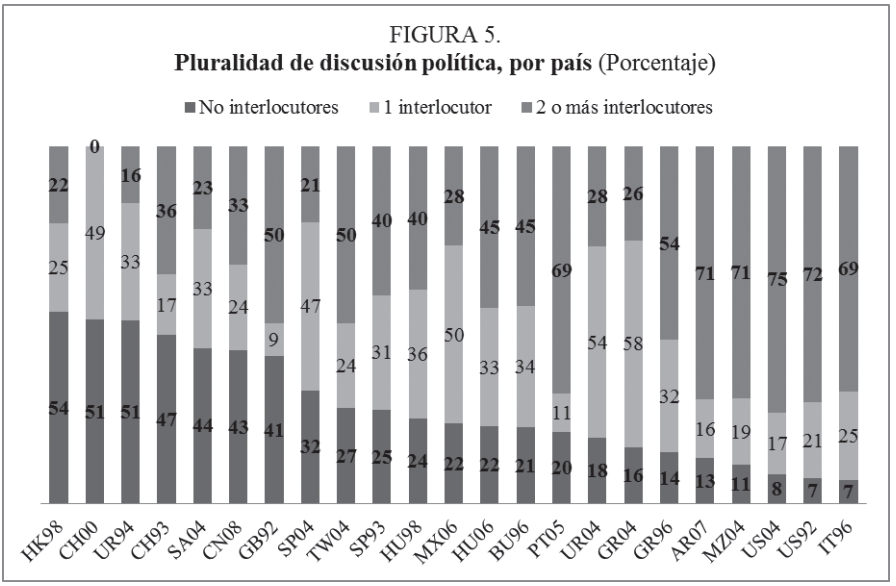

Los niveles de heterogeneidad en medios de comunicación y en la discusión interpersonal fueron bajos en todas las democracias, como puede verse en las figuras 6 y 7 . El porcentaje de los encuestados que no estaban expuestos a información discordante en discusiones políticas ni en medios heterogéneos es relativamente alto. Esto confirma que los ciudadanos tienden a buscar una exposición amigable en los medios de comunicación (Goldman y Mutz, 2011) y, especialmente, a discutir con interlocutores con quienes comparten preferencias políticas (Richardson y Beck, 2007). Aquellos con los porcentajes más altos fueron Mozambique (97,9\%), Sudáfrica (95,5\%) y Hong Kong $(92,4 \%)$, con, prácticamente, ninguna heterogeneidad de

De hecho, la correlación agregada entre países de la pluralidad de los medios de comunicación y discusiones es relativamente alta: 0,5 ( $\mathrm{p}=0,02)$. Esta correlación está también presente al nivel de los individuos: 0,26, estadísticamente significativa $\mathrm{p}<0,000$. 
exposición a los medios de comunicación. Los países que presentan el porcentaje más alto de heterogeneidad en medios de comunicación fueron Estados Unidos (61,4\%), Grecia en 1996 (72,2\%) y Taiwan (73,6\%).

Como muestra la figura 7 , la situación fue similar con respecto a la heterogeneidad en la discusión política: el orden de los países respecto a esta variable fue el mismo, con Estados Unidos con el porcentaje más bajo y los países africanos mencionados con los porcentajes más altos. La excepción fue Argentina, donde el $84 \%$ de los encuestados no mostraron heterogeneidad alguna en el uso de medios de comunicación pero el 67,7\% sí la mostró en la discusión interpersonal.

La relación a nivel agregado en el uso de ambos mecanismos de intermediación puede confirmarse por la alta correlación existente entre ambos $(0,73$ con $\mathrm{p}<0,000)$, si bien esta correlación se mitiga sustancialmente si la estimamos a nivel individual $(0,16)$.

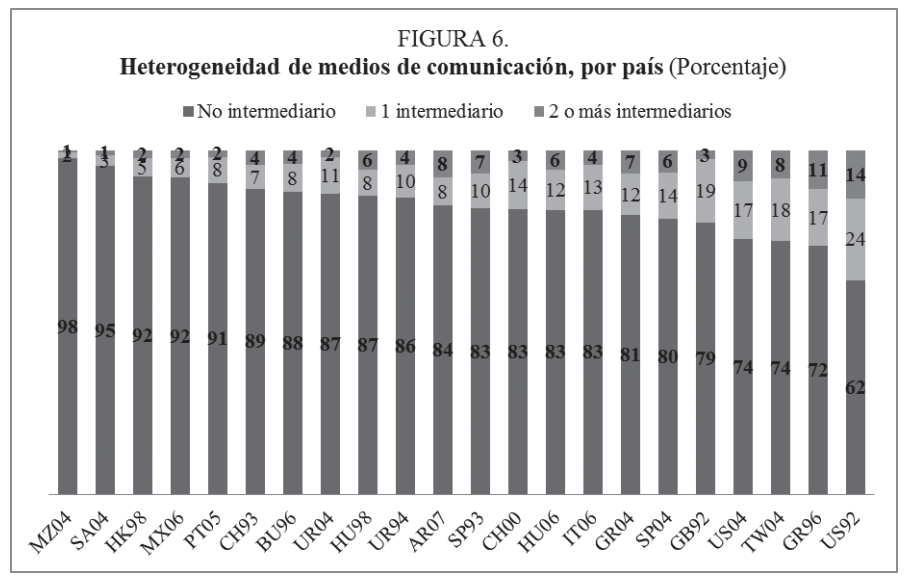




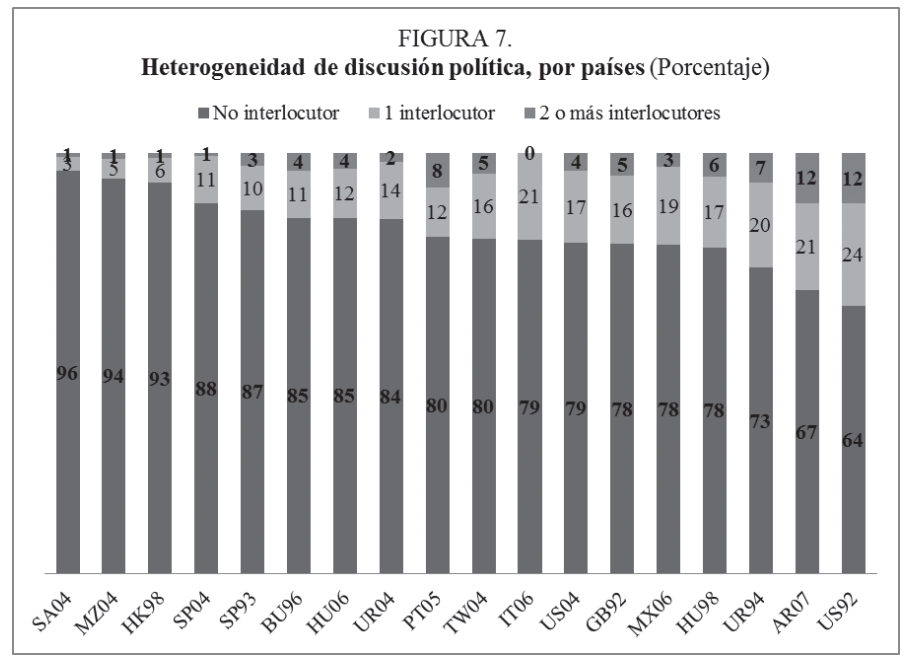

\section{Estimación inicial de los efectos de pluralidad y de heterogeneidad de intermediación}

Para poner a prueba el argumento central de este trabajo sobre los efectos de la intermediación política en las actitudes de interés y eficacia política, van a estimarse varios modelos. El primer modelo utiliza la pluralidad como la variable independiente más significada e incorpora algunas variables de control relevantes que han probado ser parte de la explicación de estas actitudes políticas: el conocimiento político, ${ }^{9}$ la identificación

Para analizar el conocimiento se han usado una serie de cuatro preguntas en el CNEP sobre aspectos de la política nacional. De este modo se crearon cuatro variables dicotómicas que al sumarse dieron como resultado una escala que va de 0 (para individuos que no respondieron ninguna pregunta correctamente) a 4 (para aquéllos que respondieron correctamente a toda la serie). 
partidista, ${ }^{10}$ así como la polarización ideológica. ${ }^{11}$ También incluimos algunas características socioeconómicas de los encuestados, como el nivel de escolaridad, la edad, el género (donde 1 equivale a ser mujer), los ingresos con una transformación logarítmica (para compensar el efecto sesgado de su distribución) y el estado civil (donde 1 indica casado o con una pareja y 0 lo contrario). Finalmente, estandarizamos todas las variables para que se encuentren entre 0 y 1 , con el fin de obtener coeficientes más comparables.

La tabla 1 presenta los resultados de la estimación de modelos logísticos ordinales con estimadores robustos ${ }^{12}$ para las tres variables dependientes: interés en política y eficacias interna y externa. En esta tabla y las siguientes, y para mayor simplicidad, sólo se presentan y comentan los coeficientes que son relevantes para el principal argumento teórico de este trabajo. ${ }^{13}$ Los resultados de esta tabla confirman que la pluralidad de la exposición a la información política de los medios de comunicación y las discusiones políticas interpersonales incrementan el interés político y la eficacia política interna, pero no tienen efecto alguno en la eficacia externa. Adicionalmente, como puede verse en la diferencia media en las probabilidades predichas, ${ }^{14}$ el efecto de la pluralidad de intermediación en el interés en la política es mayor que el que se observa

10 Medida con una variable que va desde 0 para alguien autodeclarado como "no partidario" a 3 para alguien "fuertemente partidista".

11 Esto es la distancia en términos absolutos de la posición individual de la media de la ideología política izquierda-derecha en cada país.

12 Este tipo de estimadores son necesarios dada la estructura jerárquica de los datos y la intracorrelación entre los individuos de un mismo país, lo que propicia problemas de heterocedasticidad.

13 Los resultados completos con todos los estimadores pueden solicitarse a los autores directamente.

14 Éste se calcula como la media de los cambios en las diferencias de las probabilidades predichas de cada variable independiente cuando sus valores pasan del mínimo al máximo. 
para la eficacia política interna. Asimismo, el efecto de la pluralidad en conversaciones políticas es un poco mayor que el que produce la exposición plural a los medios de comunicación.

Para mostrar el efecto positivo de la pluralidad del uso de los medios de comunicación y la discusión sobre el interés político y la eficacia política interna, se representan los efectos marginales de estas variables independientes sobre estas actitudes para cada unidad de incremento de las mismas en las figuras 8 y 9. Dichas figuras evidencian un efecto marginal positivo y significativo del uso de los medios de comunicación y la frecuencia de la discusión interpersonal en los individuos que declararon estar "muy interesados en política”. Las figuras 10 y 11 muestran el mismo efecto positivo y significativo en la eficacia política interna. Como también puede apreciarse, la frecuencia del uso de los medios de comunicación es el factor con la relación más débil con la eficacia política interna. En la tabla 1, esta variable muestra la probabilidad predicha más baja. 


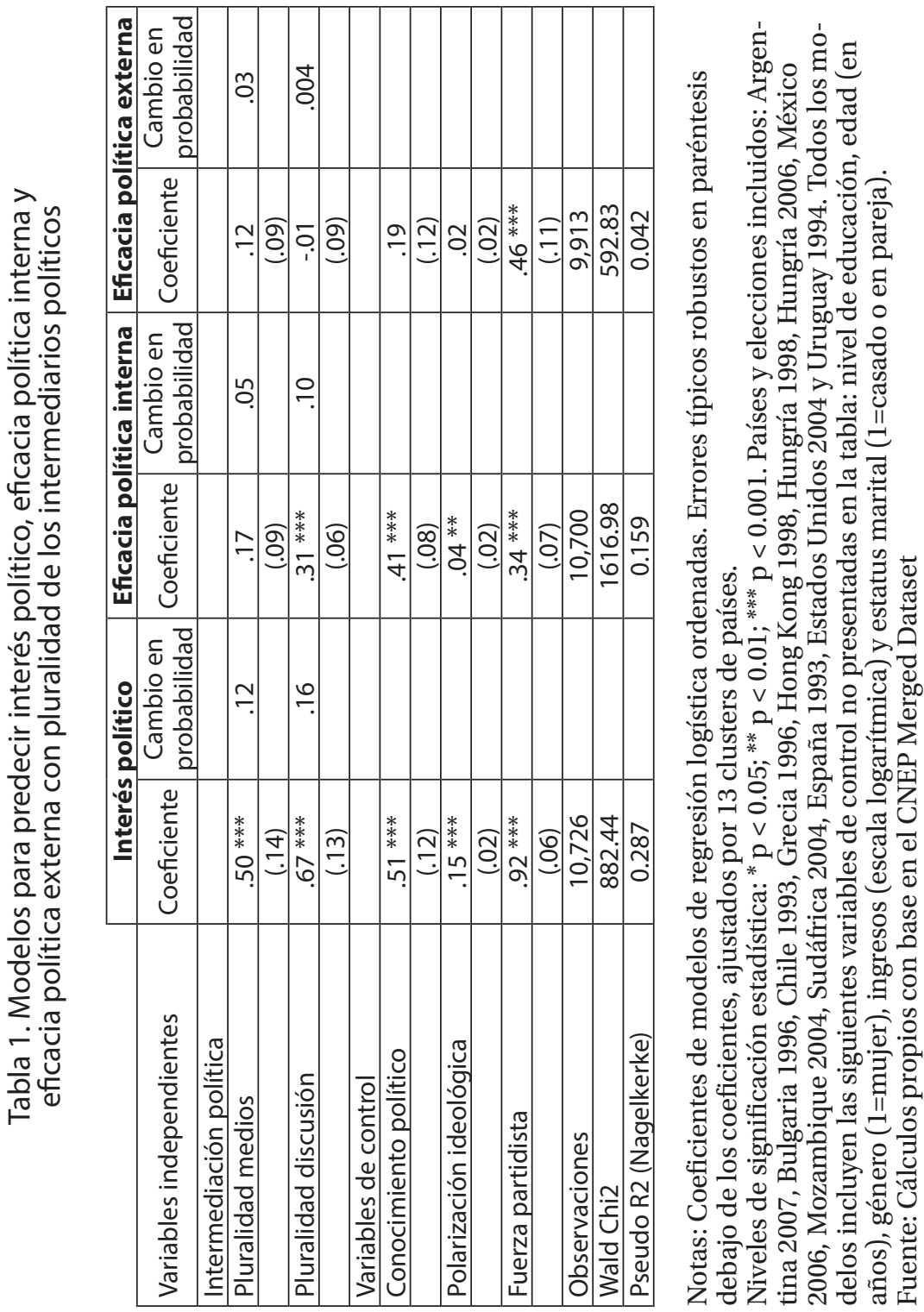


FIGURA 8. Probabilidades marginales de Interés en la política por pluralidad de medios de comunicación

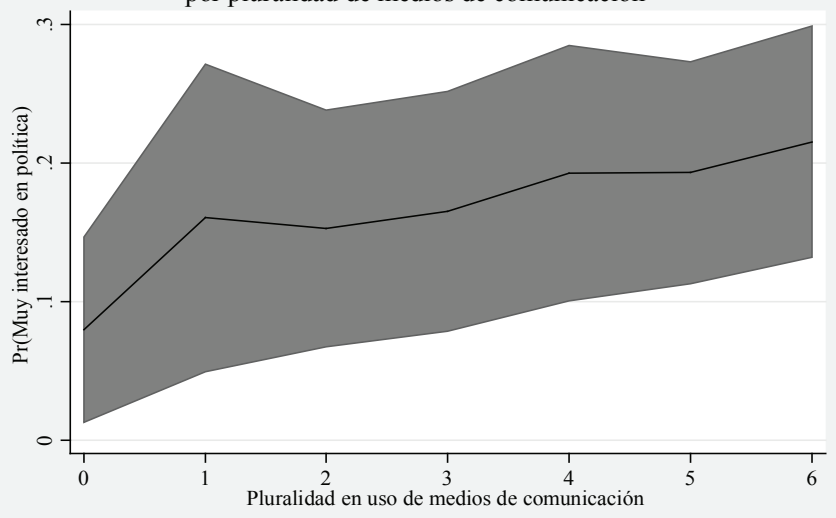

FIGURA 9. Probabilidades marginales de Interés en la política por pluralidad de discusión política

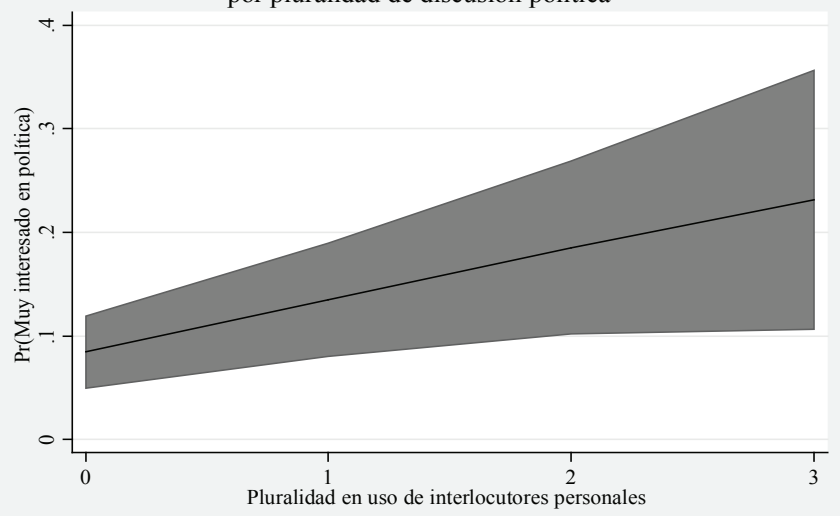


FIGURA 10. Probabilidades marginales de Eficacia política interna por pluralidad de medios de comunicación

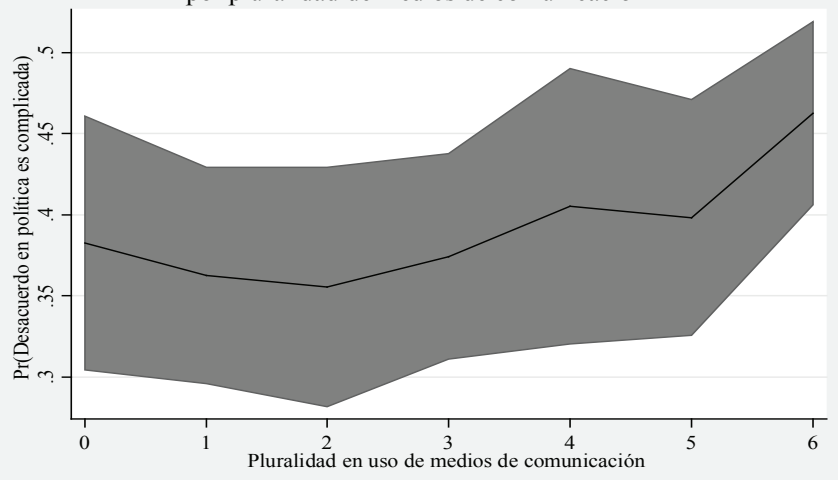

FIGURA 11. Probabilidades marginales de Eficacia política interna por pluralidad de discusión política

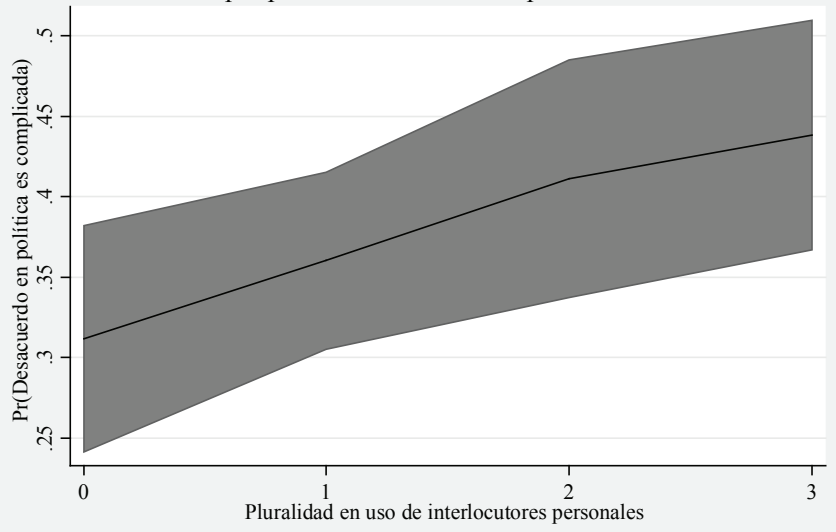


En general, estos resultados evidencian que la pluralidad de la exposición tiende a favorecer actitudes positivas para la democracia al incrementar el interés político. Sin embargo, este efecto está ausente para la eficacia política externa, algo contrario a lo que se argumenta entre los defensores de la hipótesis del "video-malaise" y "círculo virtuoso" de los medios de comunicación (Norris 2000 y 2011).

No obstante, también es necesario estimar el efecto en estas actitudes de la "heterogeneidad" o exposición "al desacuerdo informativo" en medios de comunicación y en discusiones interpersonales. Para hacerlo, se ha estimado el mismo modelo pero agregando las variables que miden heterogeneidad de la exposición. La heterogeneidad es función de la pluralidad, así que al añadir ambos estimamos el efecto puro de heterogeneidad, descontando el efecto de pluralidad. 


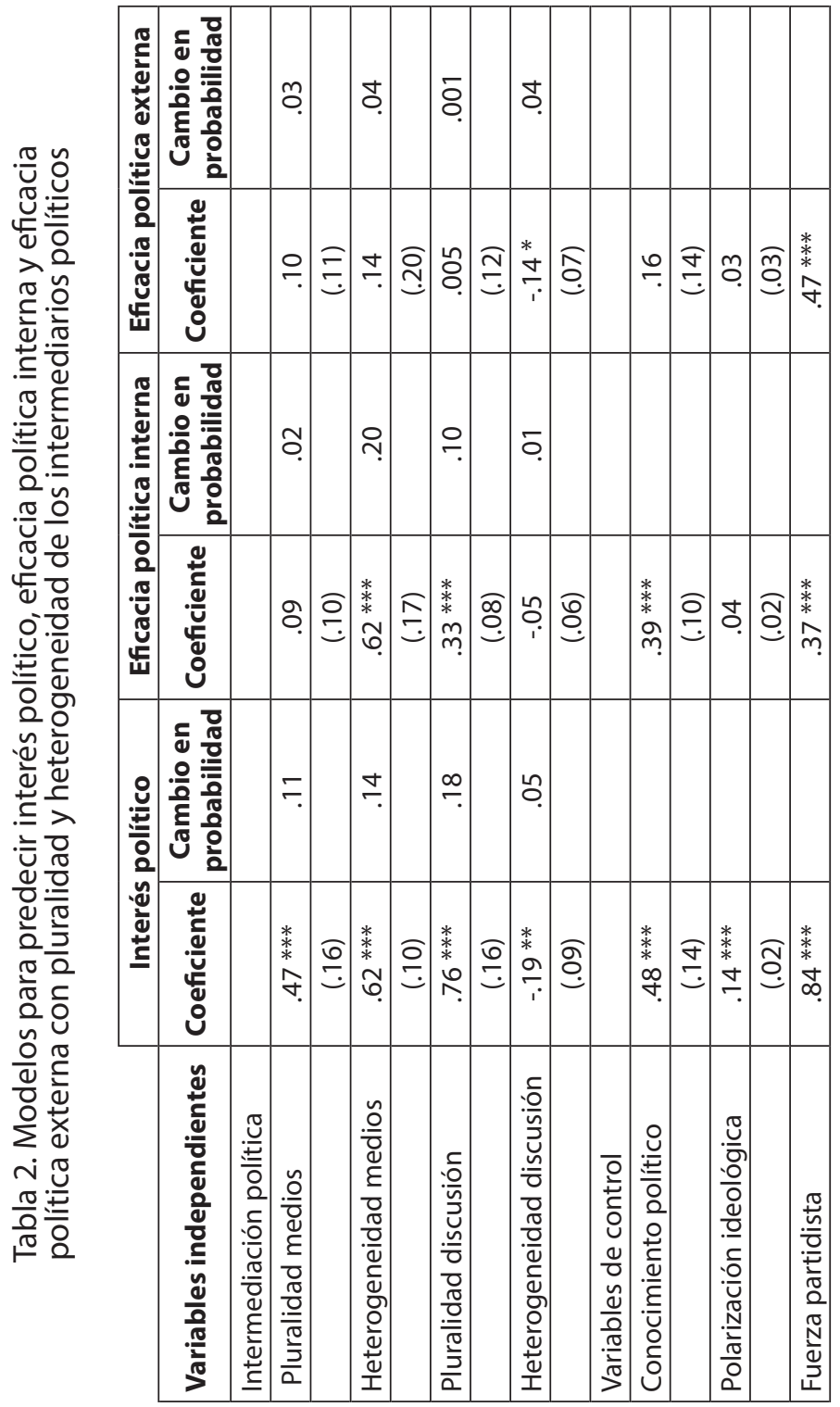




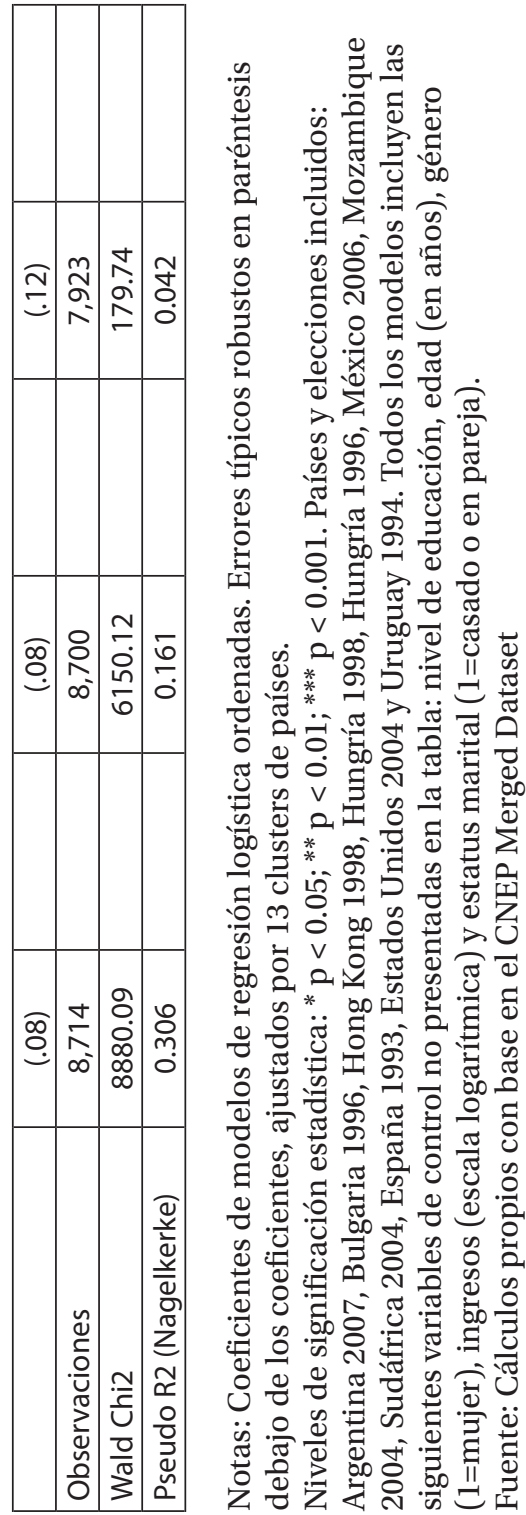


Como puede verse en la tabla 2, la pluralidad parece tener un efecto positivo en el interés político, lo que confirma nuestros resultados previos, pero la exposición a la información en desacuerdo parece tener efectos contradictorios dependiendo del tipo de intermediación. Por un lado, la exposición a la heterogeneidad informativa en los medios de comunicación incrementa el interés político; pero, por el otro, la heterogeneidad en las conversaciones políticas tiene un efecto negativo en el interés político. Esto significa que una vez que los efectos de la pluralidad pura son descontados, las discusiones heterogéneas ("conflictivas o divergentes") parecen disminuir el interés individual por la política ${ }^{15}$ Lo mismo parece ser que ocurre con la eficacia política interna y externa, aunque el coeficiente no es estadísticamente significativo en el caso de eficacia interna.

Para ilustrar el efecto negativo de la heterogeneidad de las discusiones políticas en estas actitudes, mostramos los efectos marginales de estas discusiones en el nivel más alto de interés y de eficacia interna y externa. Las figuras 12, 13 y 14 también confirman nuestros resultados y muestran que los efectos en la eficacia interna y externa son bastantes similares. El efecto negativo aumenta sustancialmente una vez que los ciudadanos están expuestos a más de dos interlocutores en desacuerdo. Los resultados de estas figuras, por tanto, muestran el potencial del "lado peligroso" de la discusión política y confirman los resultados de estudios

15 Con el fin de confirmar la robustez de nuestros resultados también analizamos otros modelos similares para aquellos individuos que sí fueron capaces de haber percibido un sesgo partidista en la información transmitida por estos intermediarios, lo cual excluyó a los encuestados que no mencionaron ningún sesgo en medios o en conversaciones políticas. Lo resultados fueron muy parecidos, lo cual confirma los modelos presentados. La única diferencia importante es que los coeficientes de las variables de medios de comunicación fueron más pequeños y los coeficientes de las conversaciones políticas fueron un poco más altos. 
anteriores que argumentaban a favor de los efectos desmovilizadores de las discusiones políticas heterogéneas (Berelson, Lazarfeld y Mc Phee, 1954; Mutz, 2002a).

FIGURA 12. Probabilidades marginales de Interés en la política por heterogeneidad de discusión política

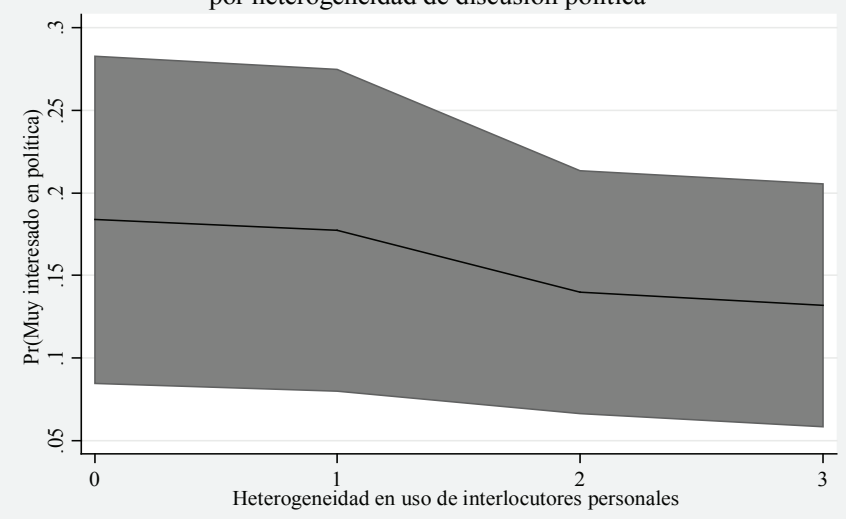

FIGURA 13. Probabilidades marginales de Eficacia política interna por heterogeneidad de discusión política

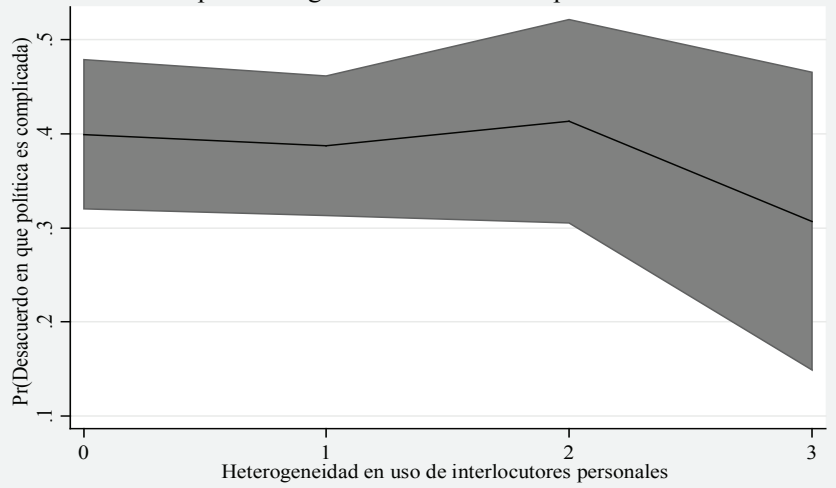




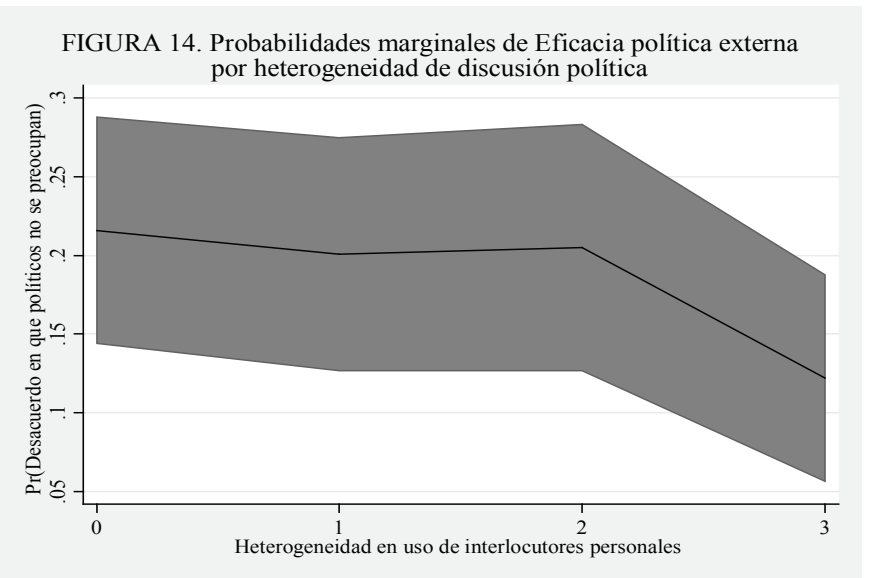

El efecto negativo de las discusiones interpersonales podría deberse, frente a lo que ocurre con la exposición heterogénea a la información en los medios, al costo personal que implica tener una interacción personal durante una discusión política que se torna conflictiva con ciudadanos con puntos de vista que difieren de los propios (Mutz 2002a: 841). Pero esto no ocurre con la simple exposición al desacuerdo en los medios de comunicación (Mutz y Martin, 2001), lo que explicaría sus consecuencias positivas en el interés político y en la eficacia política.

Finalmente, como puede verse en la tabla 2, ni la pluralidad ni la heterogeneidad en la intermediación política tienen efecto alguno en la eficacia política externa. Parece que la intermediación sólo afecta las actitudes relacionadas con el compromiso político y no aquéllas que miden la confianza en los mecanismos de representación política y la valoración de la receptividad del sistema.

Hasta ahora, se ha demostrado que nuestras expectativas eran correctas: la intermediación tiene un efecto claro 
en las actitudes políticas. La pluralidad de intermediación tiene un efecto positivo en el interés y en la eficacia interna (pero no en la eficacia externa) y el efecto de la discusión interpersonal es mayor que el efecto de la comunicación de los medios. También se ha mostrado que la exposición a la heterogeneidad informativa en los medios de comunicación hace que los ciudadanos estén políticamente interesados y comprometidos. Sin embargo, los efectos de la intermediación no son siempre positivos: la exposición a conversaciones conflictivas o en desacuerdo propicia la falta de interés en la política de los ciudadanos. Éste es nuestro aporte más relevante hasta ahora.

Podría argumentarse que los modelos precedentes tienen un problema de endogeneidad o casualidad inversa. Sin embargo, por varias razones creemos que esto no es plausible. Primero, desde un punto de vista teórico, es muy poco factible que un individuo que dice no tener interés en la política o que siente que la política es muy complicada para entenderla haya buscado conversación con uno o más interlocutores en desacuerdo. Segundo, desde una perspectiva metodológica, para controlar por la posibilidad de un estimador sesgado debido a la endogeneidad, se han estimado dos modelos: uno donde la heterogeneidad de las discusiones políticas fue instrumentada como variable independiente para predecir el interés político y otro modelo donde el interés político fue instrumentado como un predictor de la heterogeneidad en las conversaciones. Los resultados, que no mostramos aquí por razones de espacio, confirman nuestros resultados y se vuelven evidencia suficiente en apoyo a la dirección causal del argumento.

Sin embargo, este efecto negativo de la heterogeneidad en la discusión no afecta a todos los individuos por igual. Ello va a depender, por un lado, de ciertas características individuales de los entrevistados y, por el otro, de los 
distintos contextos políticos en los que dichos ciudadanos se mueven. A ello dedicaremos las siguientes páginas.

\section{El efecto condicional del conocimiento político}

Las explicaciones de los efectos potenciales de las discusiones interpersonales y de la exposición a la información de los medios de comunicación en el conocimiento político son abundantes en la literatura. Muchos tratan de evaluar si, como Jackmann y Sniderman (2006: 272) dicen, "al final de una discusión, las posiciones de las personas reflejarán su más profundo juicio sobre el asunto". La influencia externa en ese juicio, si hay alguna, proviene principalmente de abundantes atajos y pistas de información en las discusiones interpersonales (Berelson et al., 1954). Como se mencionó anteriormente, estas discusiones ocurren, en su mayoría, entre personas con preferencias similares, así que las pistas recibidas principalmente son reforzadoras.

Pero ¿qué pasa cuando los ciudadanos son expuestos a atajos y pistas en desacuerdo o contradictorios con sus preferencias? Los efectos pueden ser condicionados por el nivel del conocimiento político. Como se estableció antes, nuestra expectativa teórica es que las personas con más conocimientos pueden verse menos afectadas negativamente por el conflicto producido por la exposición a información en desacuerdo o conflictiva; mientras que los ciudadanos no sofisticados políticamente pueden tener menos recursos cognitivos para enfrentarse a mensajes de confrontación y, como resultado, pueden tener una reacción más negativa a la "información divergente".

En los modelos anteriores se ha incluido el conocimiento político como una variable de control, pero ahora se quiere comprobar si los efectos de las discusiones heterogéneas en el interés político o en la eficacia política 
interna están condicionados por el nivel del conocimiento político. Para comprobar esto, hemos divido la muestra entre individuos con cierto nivel de conocimiento político e individuos con muy poco conocimiento político. Si nuestra expectativa es correcta, el efecto negativo de la heterogeneidad de la comunicación debería estar presente sólo entre individuos no sofisticados.

Los resultados de las estimaciones de los modelos con las dos submuestras diferentes se encuentran en la tabla 3. Como se esperaba, los efectos negativos de la heterogeneidad de la discusión política son significativos entre ciudadanos no sofisticados. Éste fue el resultado para el interés político y la eficacia política externa para esta submuestra, con coeficientes estadísticamente significativos de -0,023 y -0,022, respectivamente. Sin embargo, este efecto está ausente en la eficacia política interna. Mientras tanto, una vez más, el efecto de la exposición heterogénea a los medios de comunicación es positivo y lo mismo para ambos niveles de conocimiento político: el efecto de pluralidad es el mismo para todas las submuestras. Sólo la pluralidad de los medios de comunicación parece tener un efecto positivo en la eficacia externa entre los votantes no sofisticados. 


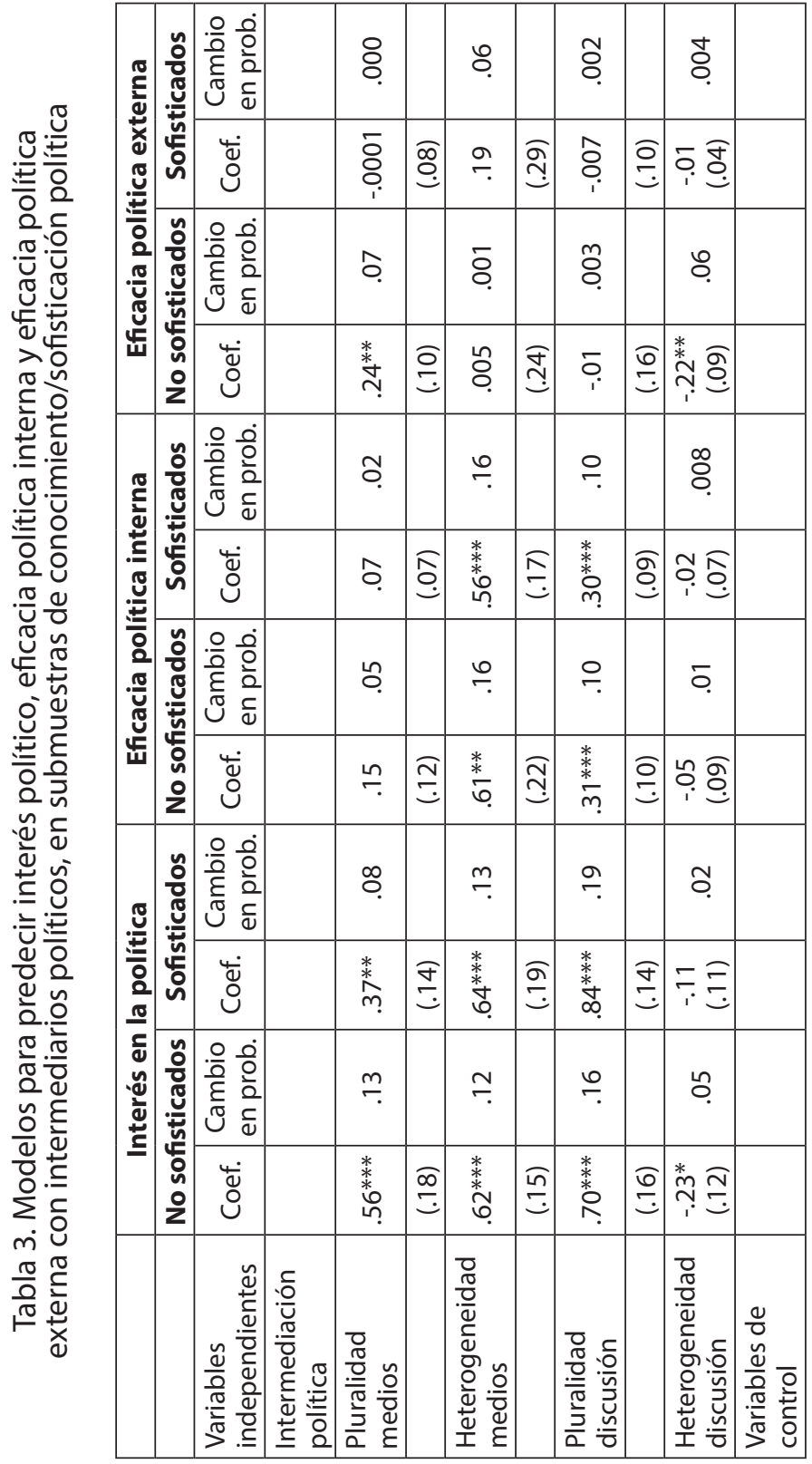




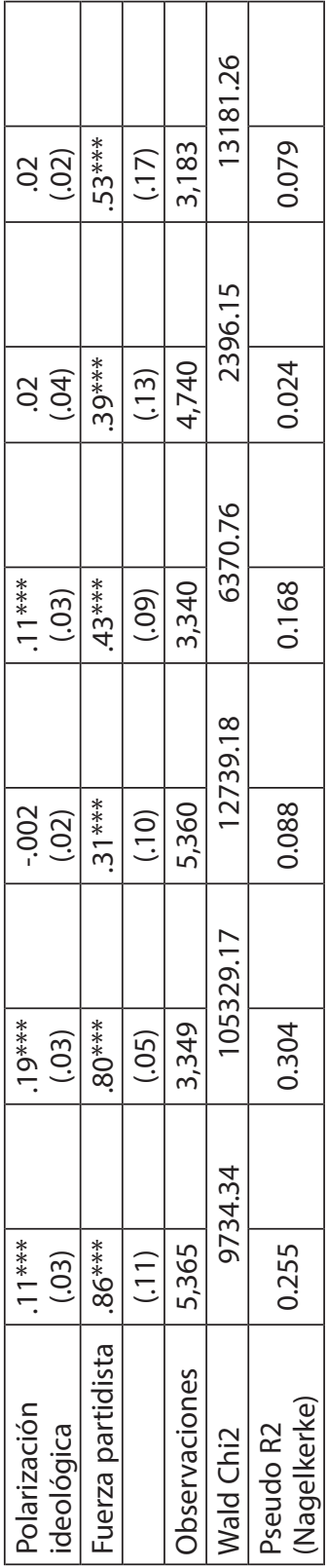

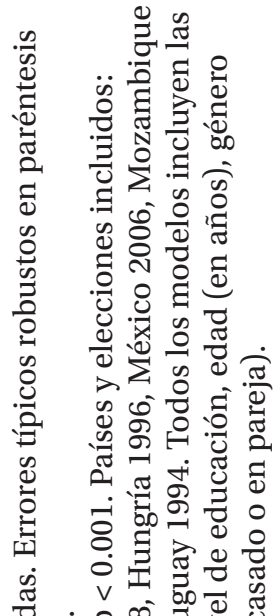

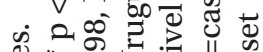

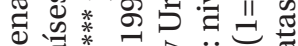
금

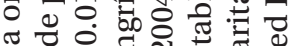

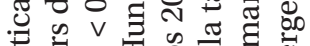

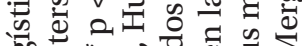
Б八

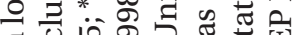
능 1

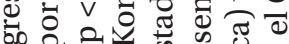

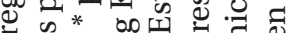
○ 필.

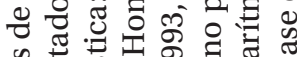
क ग्रु

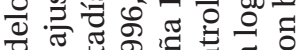

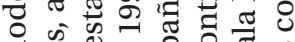

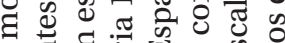
๑ సีత

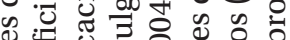

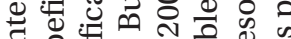

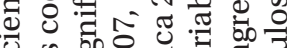

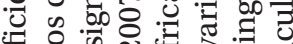
으 "

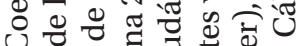

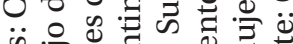

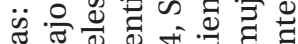

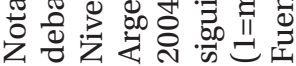




\section{Los efectos condicionales del partidismo y el conflicto político}

Como se ha señalado en las secciones previas, la heterogeneidad de las discusiones interpersonales puede tener consecuencias negativas en la desmovilización de los ciudadanos y hacerlos menos atentos a la esfera pública y menos involucrados políticamente. Pero esos efectos pueden estar condicionados por la naturaleza del conflicto en una sociedad dada: entre mayor sea el conflicto, mayor será el costo personal de las discusiones en desacuerdo.

También como se argumentó antes, la exposición heterogénea debe tener un impacto mayor entre partidistas fuertes. La conversación con individuos que tienen diferentes puntos de vista debe tener un impacto mayor en ciudadanos con una fuerte identificación partidaria, pues tienen que lidiar especialmente con el malestar del desacuerdo. Así la expectativa teórica es que las discusiones políticas heterogéneas tengan un impacto más negativo en esas actitudes para los individuos con una fuerte identificación partidaria, mientras que el efecto de los medios de comunicación debe mantenerse positivo sin importar la presencia o la ausencia de partidismo.

Para probar esto, se ha dividido a los encuestados de acuerdo a la presencia o la ausencia de partidismo, estimando los mismos modelos anteriores. Como se observa en la tabla 4, los resultados muestran que la heterogeneidad de las discusiones interpersonales tiene un efecto negativo y estadísticamente significativo en el interés político entre partidarios, mientras que este efecto desaparece para aquéllos sin partidismo. 
El mismo patrón fue observado para la eficacia política interna y externa. Estos resultados muestran la importancia del partidismo en el aumento del efecto negativo en estas actitudes de la discusión política heterogénea. Es importante mencionar que el efecto en estas actitudes es siempre positivo para la información heterogénea de los medios de comunicación, sin importar la presencia o la ausencia de partidismo, lo que confirma el efecto positivo de la exposición a los medios de comunicación a la hora de crear ciudadanos más comprometidos políticamente. 


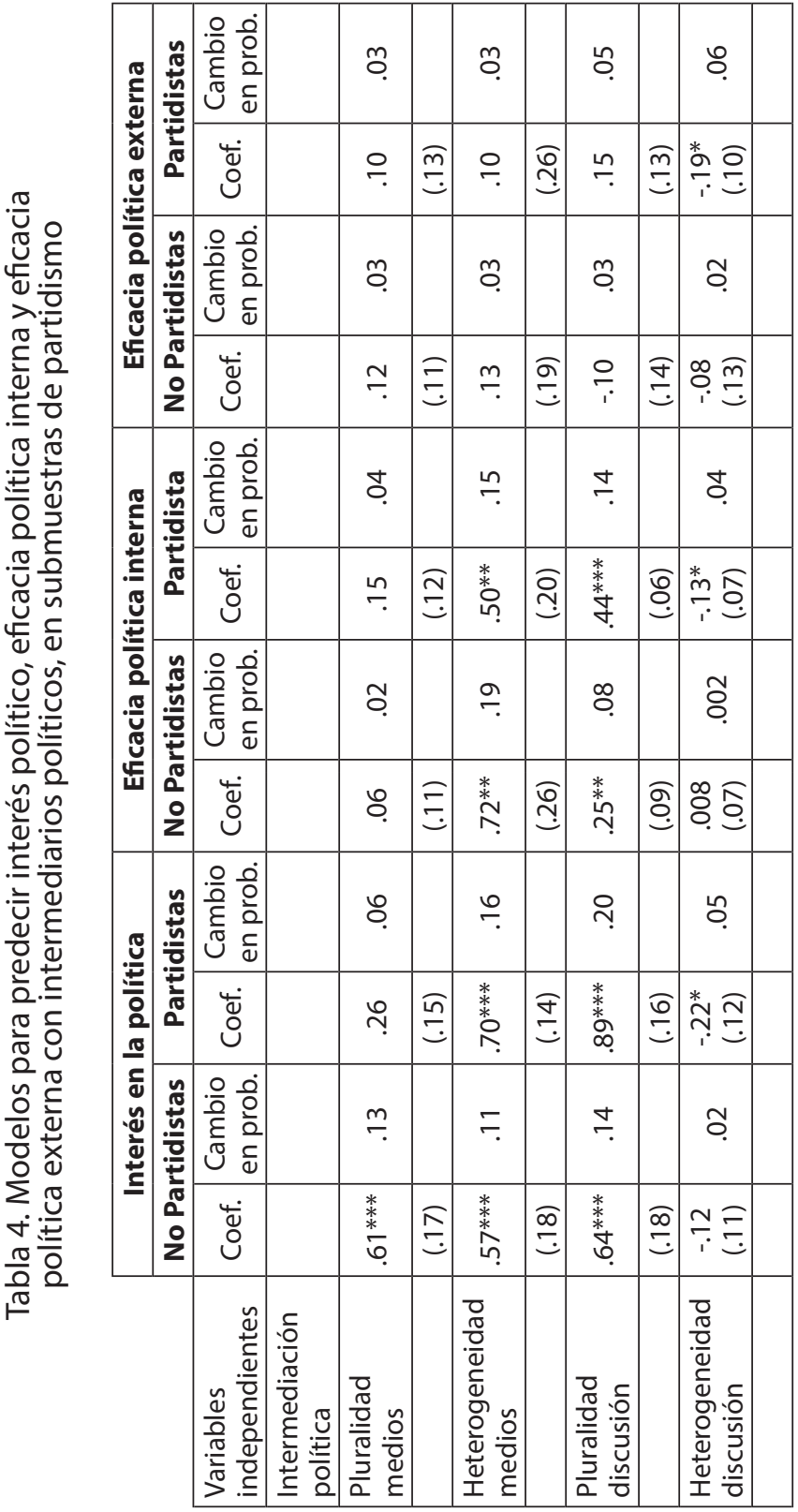




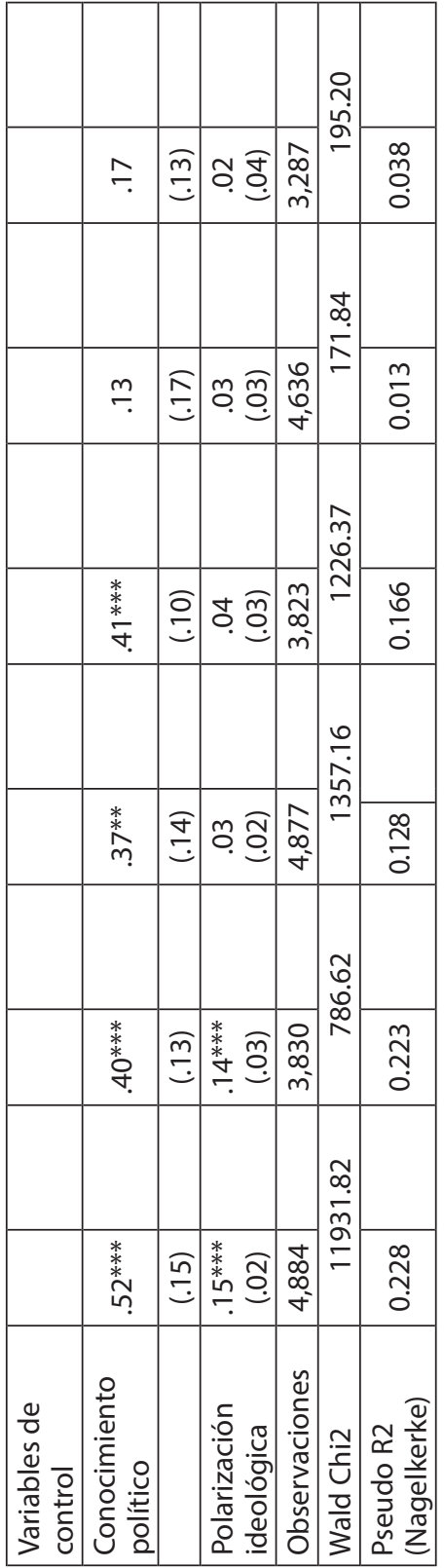

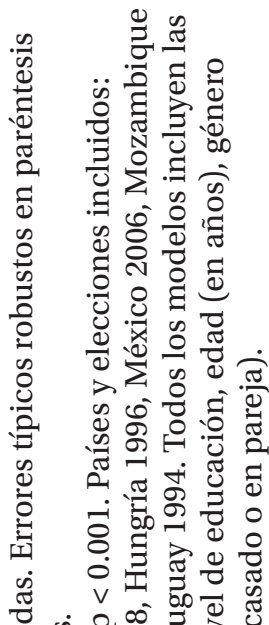

䒕

㓂

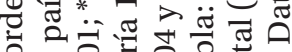

ช ข

-

क 仓 2 I 을 क

क क *

ป

그웅 0 o

$\checkmark v$ D

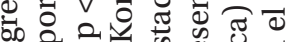

(1)

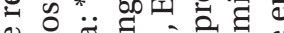

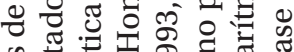

क क क

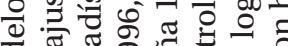

क क ब

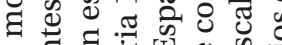

ญ

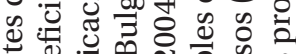

式

- $\frac{0}{0}$ क

으

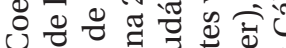

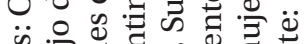

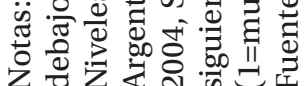


El efecto de pluralidad en la intermediación política y en la exposición heterogénea en las actitudes puede estar también condicionado por factores contextuales. Mutz y Martin (2001) han mostrado que el efecto de la exposición a los medios de comunicación depende del nivel agregado del partidismo de los medios de comunicación. Anderson y Paskeviciute (2005) encontraron que la frecuencia de la discusión política aumenta en países con un alto grado de heterogeneidad en las preferencias políticas de los partidos políticos. En ese sentido, la polarización puede incrementar el efecto negativo de la exposición heterogénea, ya que entre más grande sea la distancia ideológica entre los distintos grupos políticos y sociales mayor será la encapsulación y mayor la incomodidad personal con el desacuerdo. Así, los efectos negativos de la heterogeneidad de las conversaciones políticas deben ser mayores en sistemas de partidos más polarizados.

El efecto condicionado de la relación entre estas variables por la fragmentación del sistema de partidos es diferente. Como Huckfeldt et al. (2005) afirman, la heterogeneidad política es mayor en grupos grandes debido a su mayor número, mientras que los grupos minoritarios tienden a estar menos expuestos a la heterogeneidad de grupos. Lo contrario es también verdad: en los intercambios entre partidos, la heterogeneidad entre ellos es menor en configuraciones fragmentadas de grupos minoritarios, mientras que la heterogeneidad entre partidos aumenta entre grupos o partidos grandes. Por lo tanto, en sistemas de partidos fragmentados, los ciudadanos deben estar más acostumbrados a mayor heterogeneidad entre grupos, mientras que el fenómeno está ausente en sistemas de partidos menos fragmentados. Así, los efectos negativos de la heterogeneidad de las discusiones en actitudes políticas democráticas deberían ser mayores en sistemas de partidos menos fragmentados. Por ello, este efecto contraproducente 
de la exposición a la información en desacuerdo en estas actitudes es significativo y mayor en sistemas de partidos más polarizados y menos fragmentados.

Para probar este argumento se usan dos diferentes medidas agregadas: un índice de polarización del sistema de partidos calculado a partir de la variación promedio de la posición ideológica de los votantes de los principales partidos ponderado por el voto compartido de cada partido (Dalton, 2008) y la fragmentación del sistema de partidos medida por el número efectivo de partidos políticos (Laakson y Taagapera, 1979; Gallaguer y Mitchells 2009). La distribución por país y año para ambos índices está en la tabla 5.

La polarización del sistema de partidos varía mucho entre los países y las elecciones que son objeto de estudio en este trabajo. Los sistemas menos polarizados fueron Argentina en 2007 y Sudáfrica en 2004 (con puntuaciones medias de variación de 2,07 y 3,87, respectivamente); los más polarizados fueron Italia en 2006 (con 10,5) y Hungría en 2006 (con 9,95). También hay una gran variación en la fragmentación. Los sistemas de partidos más fragmentados fueron el de Italia (con 7,17 partidos en 1996 y 5,69 en 2006) y el de Hungría (con 5,18 en 1998); y los menos fragmentados fueron Sudáfrica (con 1,97 partidos en 2004) y Mozambique (con 2,11 en 2004), seguidos de cerca por Estados Unidos (con 2,14 partidos 1992 y 2,18 partidos en 2004). 
Tabla 5. Índices de polarización y fragmentación para los países y elecciones del CNEP

\begin{tabular}{|l|c|c|}
\hline \multicolumn{1}{|c|}{$\begin{array}{c}\text { País y año de } \\
\text { elección }\end{array}$} & $\begin{array}{c}\text { Índice de polariza- } \\
\text { ción del sistema de } \\
\text { partidos * }\end{array}$ & $\begin{array}{c}\text { Índice de fragmen- } \\
\text { tación del sistema } \\
\text { de partidos ** }\end{array}$ \\
\hline Argentina 2007 & 2.07 & 3.40 \\
\hline Bulgaria 1996 & 9.77 & 3.01 \\
\hline Chile 1993 & 7.27 & 6.76 \\
\hline Chile 2000 & n.d. & 6.56 \\
\hline Grecia 1996 & 7.62 & 3.07 \\
\hline España 1993 & 6.22 & 3.52 \\
\hline España 2004 & 7.84 & 3.00 \\
\hline Estados Unidos 1992 & n.d. & 2.14 \\
\hline Estados Unidos 2004 & 6.22 & 2.18 \\
\hline Grecia 2004 & 7.48 & 2.66 \\
\hline Hong Kong 1998 & 4.25 & n.d. \\
\hline Hungría 1998 & 4.18 & 5.18 \\
\hline Hungría 2006 & 9.95 & 2.80 \\
\hline Italia 1996 & 8.89 & 7.17 \\
\hline Italia 2006 & 10.59 & 5.69 \\
\hline México 2006 & 4.33 & 3.42 \\
\hline Mozambique 2004 & 7.42 & 2.11 \\
\hline Portugal 2005 & 5.88 & 3.13 \\
\hline Sudáfrica 2004 & 2.87 & 1.97 \\
\hline Uruguay 1994 & 7.42 & 3.36 \\
\hline Uruguay 2004 & 9.16 & 2.49 \\
\hline
\end{tabular}

*Fuente: Cálculos propios utilizando el CNEP Merged dataset con base en Dalton (2008)

** Número efectivo de partidos políticos electorales (NEPPE). Fuente: Michael Gallaguer y Paul Mitchells (2009), The Politics of Electoral Systems, Oxford, Oxford University Press y página electronica de Michael Gallagher: www.tcd.ie/Political_Science/Staff/michael_gallagher, updated: 12 Octubre 2011. Nota: n.d. = no disponible. La información de China, Indonesia y Taiwán no estuvo disponible. 
Se ha dividido la muestra por la media de ambos índices agregados, estimando el mismo modelo para cuatro submuestras: países con baja polarización, países con alta polarización, países con baja fragmentación del sistema de partidos y países con alta fragmentación del sistema de partidos.

Las tablas 6 y 7 muestran, respectivamente, los resultados de estos cuatro modelos para el interés político y la eficacia política interna. El resultado confirma nuestras expectativas y evidencia que las conversaciones políticas heterogéneas producen más efectos negativos en el interés político en contextos de alta polarización ideológica y sistemas de partidos menos fragmentado (tabla 6). Sin embargo, el resultado no es fuerte ni tampoco significativo para la eficacia política interna (tabla 7). Los efectos positivos de la pluralidad de las discusiones en estas actitudes en contextos de baja fragmentación o de baja polarización son algo menores. El efecto de las noticias de los medios de comunicación (en términos de pluralidad y heterogeneidad) es el mismo para los cuatro contextos políticos distintos: siempre positivo. El contexto no genera ninguna diferencia respecto de la ausencia general de incidencia de la intermediación en la eficacia política externa (resultado no mostrado). 


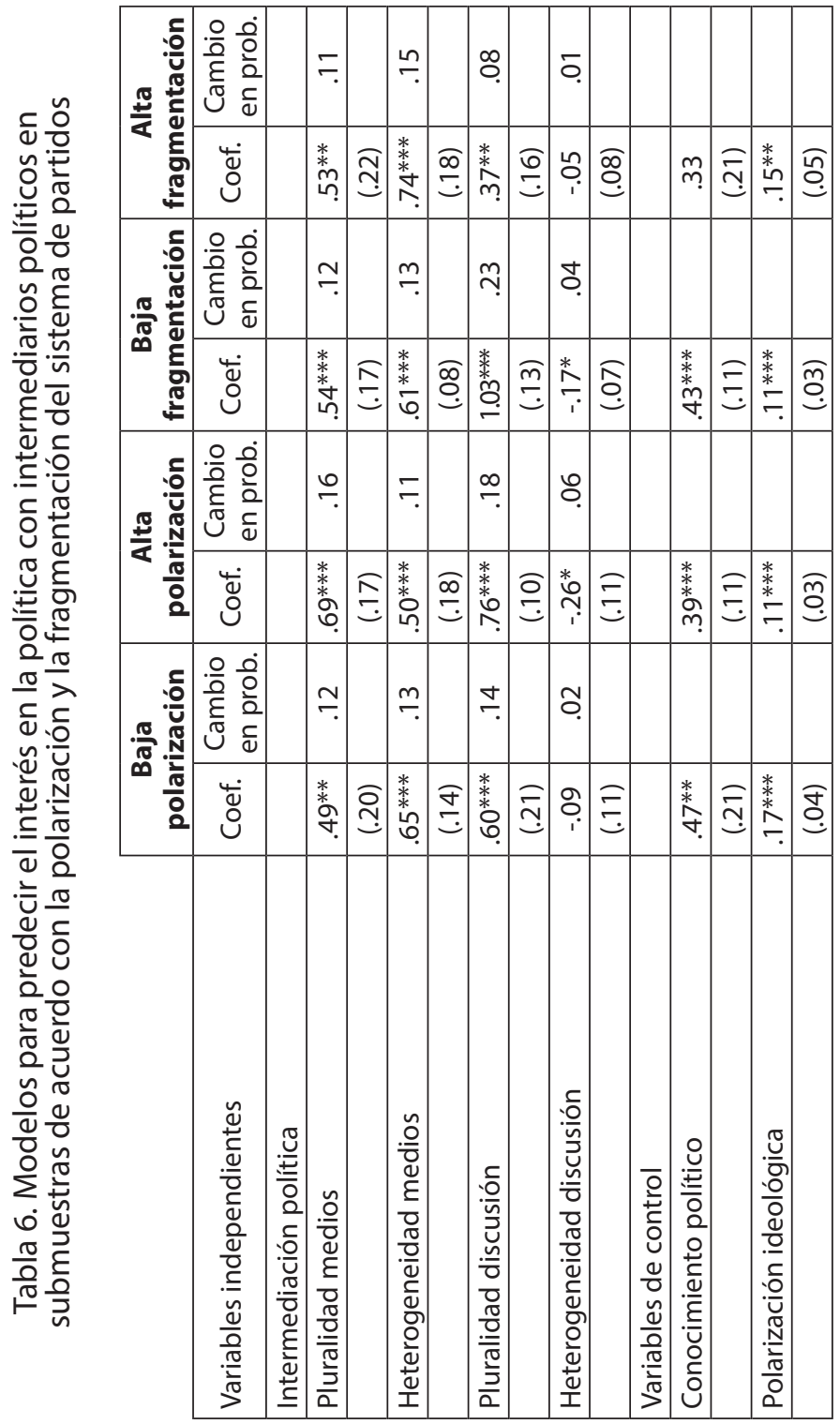




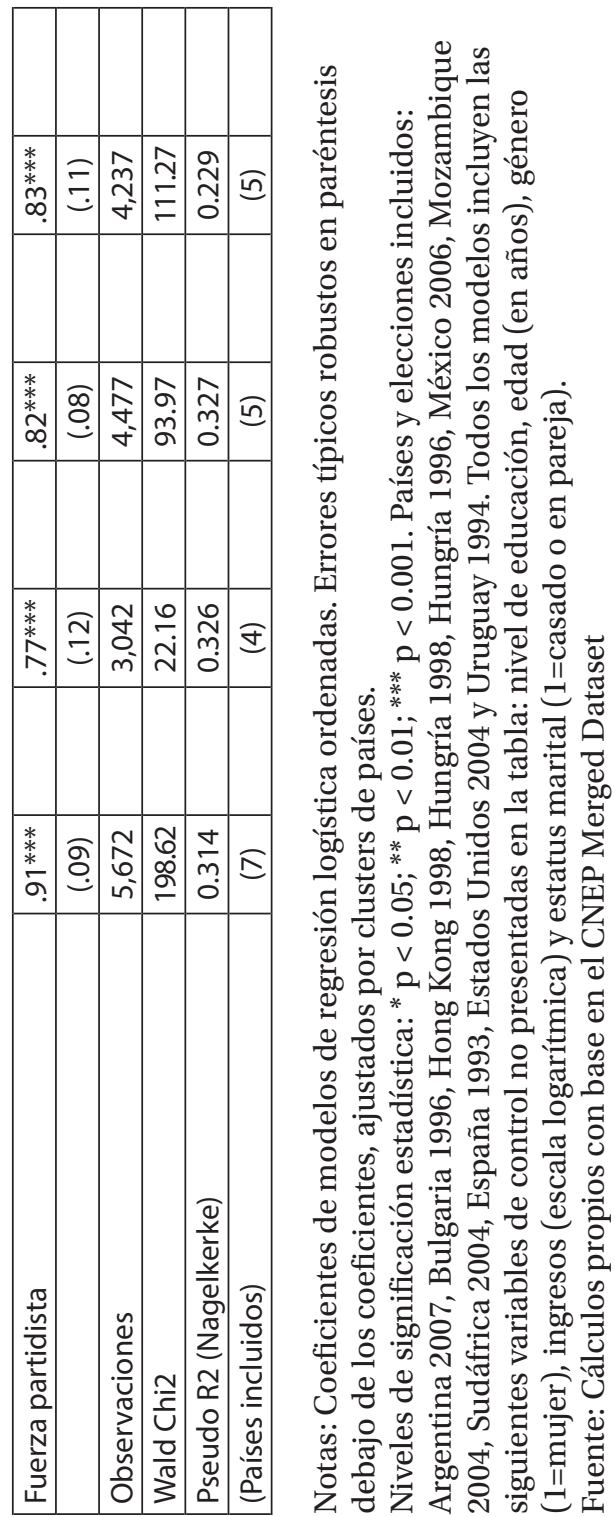




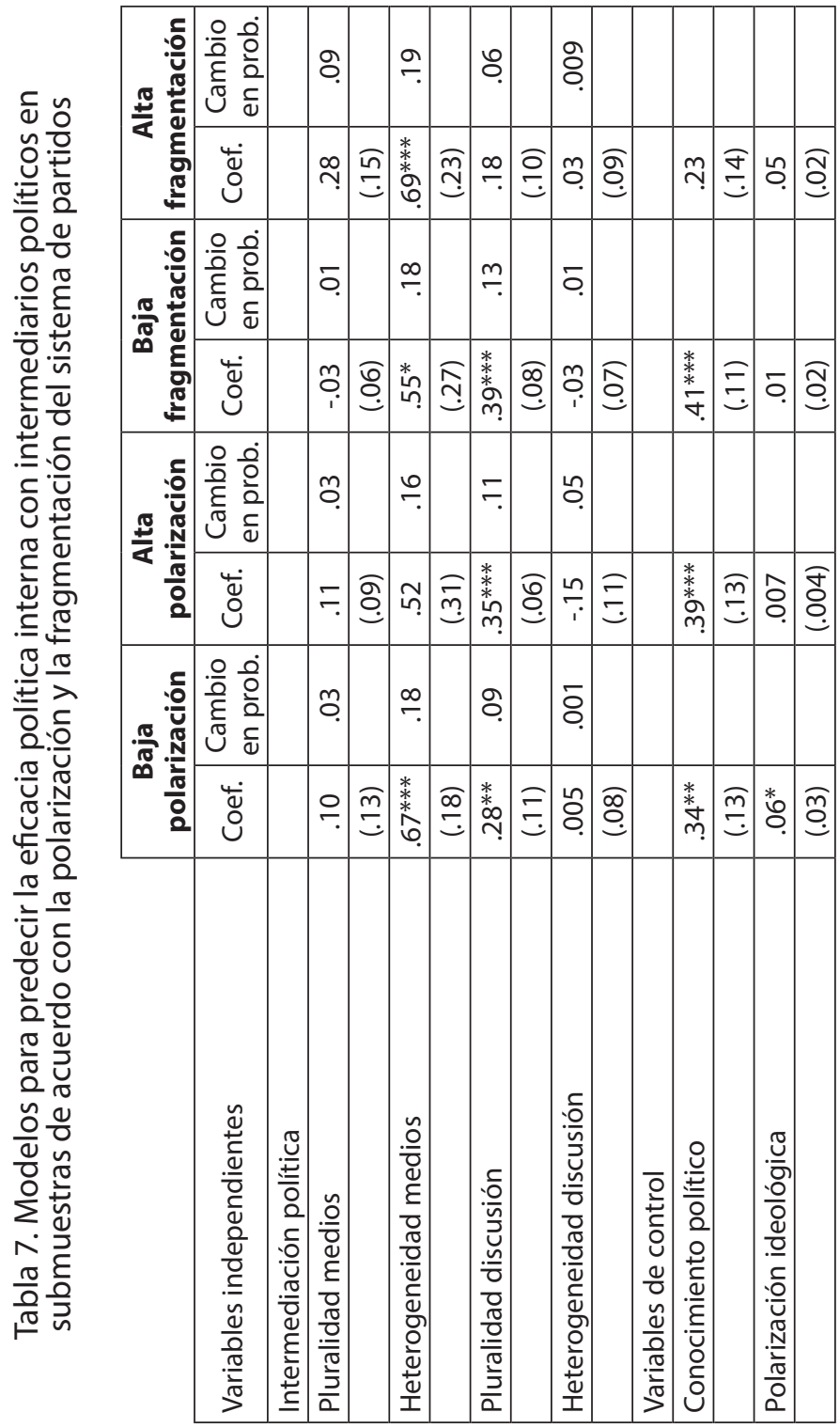




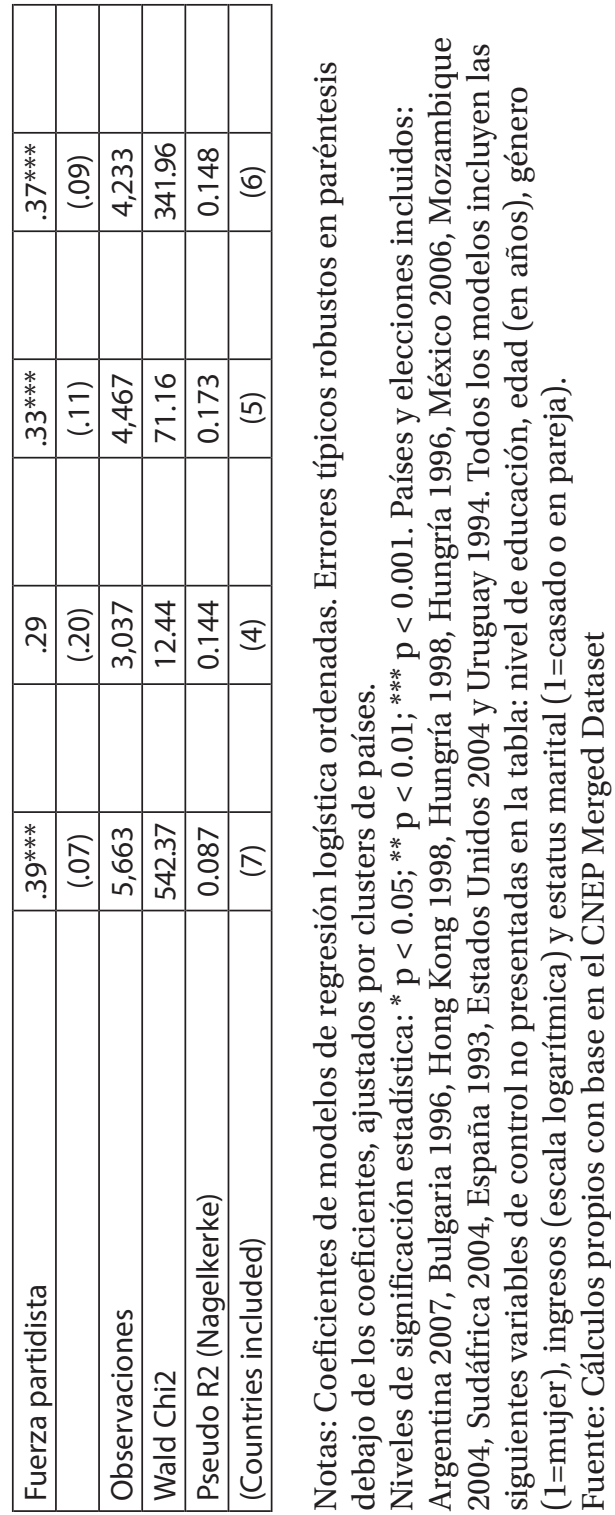




\section{Conclusiones}

La tesis central defendida en este artículo es que la deliberación política tiene consecuencias actitudinales claras para la democracia: en términos generales, hace mejores ciudadanos. Pero no todo intercambio de información es beneficioso. Cierto tipo de intermediación en circunstancias específicas puede ser perjudicial para la democracia y producir desafección política. Mientras algunas especialistas encontraron que la deliberación política tenía consecuencias positivas en el comportamiento y las actitudes ciudadanas, otros sostenían que la misma deliberación política producía una ciudadanía más apática y crítica con las instituciones representativas. Los hallazgos de este trabajo aspiran a llenar algunos vacíos y a resolver algunas de estas contradicciones en la literatura.

En primer lugar, se ha mostrado que existen diferencias entre los países respecto de las actitudes democráticas de sus ciudadanos, tanto en el nivel de interés en la política como en las eficacias políticas, interna y externa. Sin embargo, la ordenación de los países de acuerdo a estas actitudes no revela patrones relativos a la edad de la democracia o a la distribución del ingreso y la riqueza de los mismos. La única tendencia que se encontró es que en los países donde los datos fueron recogidos en dos elecciones distintas, el porcentaje de los ciudadanos interesados en la política o con sentimiento de eficacia política incrementa durante el tiempo.

Respecto a los intermediarios políticos estudiados en este trabajo, se ha encontrado que la mayoría de los ciudadanos en todos los países están expuestos al menos a un medio masivo de comunicación. También se ha observado que hay mayor exposición a los medios de comunicación que a la discusión interpersonal; esto es, los medios parecen ser más importantes para transmitir información 
al electorado que la discusión interpersonal. Además, el grado de exposición a distintas fuentes de información es distinto del nivel de desacuerdo o de información heterogénea transmitida mediante estas fuentes o intermediarios: el porcentaje de ciudadanos que estuvieron expuestos a información en desacuerdo en las conversaciones políticas o a medios heterogéneos es bastante bajo en muchos países. Esto confirma que los ciudadanos tienden a buscar una exposición amigable en los medios de comunicación (Goldman y Mutz, 2011) y, especialmente, a discutir con interlocutores con quienes comparten preferencias políticas (Richardson y Beck, 2007).

Además de estos resultados descriptivos, se ha evidenciado que los efectos de estos mecanismos de intermediación no son los mismos para las actitudes políticas de todos los ciudadanos. La exposición a mayor diversidad de información de los medios de comunicación afecta positivamente los intereses del ciudadano en política y sus sentimientos de compromiso político y competencia. La frecuencia en las conversaciones políticas también afecta positivamente el interés político y la eficacia interna. Más aun, aunque los niveles agregados mostraron que los individuos utilizan más los medios de comunicación que las conversaciones políticas, el efecto de los primeros es menor que el de la comunicación interpersonal. La diversidad en la información de los medios masivos de comunicación influye positivamente el interés en la política y la eficacia política interna. El interés político y el sentido de la eficacia se incrementan no sólo como una consecuencia de la exposición a más medios de comunicación, sino también debido a que la información recibida es más heterogénea.

Sin embargo, un hallazgo importante es que la discusión interpersonal con personas en desacuerdo tiene un efecto negativo en el interés en la política y en la eficacia interna. El interés político aumenta cuando el ciudadano 
es expuesto a más interlocutores personales, pero la exposición a presiones cruzadas o a opiniones divergentes en esas discusiones disminuye el compromiso con la política.

Además, este efecto negativo de la deliberación política está condicionado por características del individuo y el sistema político. Los efectos negativos de las discusiones con personas en desacuerdo están condicionadas por el efecto del conocimiento político del ciudadano: los individuos no sofisticados tienen mayores dificultades cognitivas al enfrentarse con discusiones conflictivas, haciendo la experiencia más desagradable y produciendo consecuencias más negativas para el compromiso político y el sentido del involucramiento político. Este efecto negativo está también, sorprendentemente, presente para el sentido de la eficacia política externa.

Finalmente, como se esperaba, la naturaleza del conflicto político y su encapsulación en la sociedad son condiciones altamente importantes que inciden indirectamente en los efectos negativos de la discusión política heterogénea. Se ha mostrado que la exposición heterogénea a discusiones políticas es significativamente más negativa para los ciudadanos cuando su partidarismo es fuerte, lo que hace el intercambio de opiniones más conflictivo y costoso. También es negativo en países cuyo sistema de partidos está más polarizado o menos fragmentando, dada la mayor encapsulación del conflicto y la competencia de los partidos.

\section{Referencias bibliográficas}

Almond, Gabriel A. y Sidney Verba (1963), The Civic Culture: Political Attitudes and Democracy in Five Nations, Princeton, Princeton University Press. 
Anderson, Christopher J. y Aida Paskeviciute (2005), "Macro-Politics and Micro-Behavior: Mainstream Politics and the Frequency of Political Discussion in Contemporary Democracies", en Alan S. Zuckerman (ed.), The Social Logic of Politics: Personal Networks as Context for Political Behavior, Philadelphia, Temple University Press.

Arendt, Hannah (1968), Between Past and Future: Eight Exercises in Political Thought, Nueva York, Viking Press. Avery, James M. (2009), "Videomalaise or Virtuous Circle? The Influence of the News Media on Political Trust", International Journal of Press-Politics, 14, pp. 410-433. Bächtinger, André y Seraina Pedrini (2010), "Dissecting Deliberative Democracy: A Review of Theoretical Concepts and Empirical Findings", en Michael Wolf, Laura Morales y Ken'ichi Ikeda (eds.), Political Discussion in Modern Democracies: A Comparative Perspective, Londres, Routledge.

Bartels, Larry (1993), “Messages Received: The Political Impact of Media Exposure", American Political Science Review, 87, pp. 267-285.

Beck, Paul Allen, Russell J. Dalton, Steven Greene y Robert Huckfeldt (2002), "The Social Calculus of Voting: Interpersonal, Media, and Organizational Influences on Presidential Choice", American Political Science Review, 96, pp. 57-74.

Berelson, Bernard R., Paul F. Lazarfeld y William McPhee, (1954), Voting: A Study of Opinion Formation in a Presidential Campaign, Chicago, The University of Chicago Press.

Campbell, Angus, Gerald Gurin y Warren E. Miller (1954), The Voter Decides, Evanston, Row, Peterson \& Company. Campbell, Angus, Phillip Converse, Warren E. Miller y Donald Stokes (1960), The American Voter, Nueva York, John Wiley \& Sons, Co. 
Carlin, Ryan E. y Gregory J. Love (2013), “The Politics of Interpersonal Trust and Reciprocity: An Experimental Approach", Political Behaviour, 35, pp. 43-63.

Dalton, Russell J. (2004), Democratic Challenges, Democratic Choices: The Erosion of Political Support in Advanced Industrial Democracies, Nueva York, Oxford University Press.

_-(2008) “The Quantity and the Quality of Party Systems: Party System Polarization, its Measurement, and its Consequences", Comparative Political Studies, 41 (7), pp. 899-920.

Delli Carpini, Michael X. y Scott Keeter (1989), What Americans know about politics and why it matters, New Haven, Yale University Press.

Delli Carpini, Michael X., Fay Lomax Cook y Lawrence R. Jacobs (2004), "Public Deliberation, Discursive Participation, and Political Engagement: An Empirical Review of the Literature", Annual Review of Political Science, 7, pp. 315-344.

Denters, Bas, Oscar Gabriel y Mariano Torcal (2007), “Norms of Good Citizenship", en Jan van Deth, Anders Westholm y José Ramón Montero (eds.), Citizenship and Involvement in European Democracies: A Comparative Analysis, Londres, Routledge.

Elster, Jon (1998), "Introduction”, en Jon Elster (ed.), Deliberative Democracy, Nueva York, Cambridge University Press.

Eveland Jr, William P., y Myiah H. Hively (2009), "Political Discussion Frequency, Network Size, and Heterogeneity of Discussion as Predictors of Political Knowledge and Participation", Journal of Communication, 59, pp. 205-224.

Eveland Jr, William P. y Tiffany Thompson (2006), “Is It Talking, Thinking, or Both? A Lagged Dependent 
Variable Model of Discussion Effects on Political

Knowledge", Journal of Communication, 56, pp. 523-542. Fearon, James D. (1998), “Deliberation as Discussion”, en Jon Elster (ed.), Deliberative Democracy, Nueva York, Cambridge University Press.

Fishkin, James S. (1991), Democracy and Deliberation:

New Directions for Democratic Reform, New Haven, Yale University Press.

-_(1997), The Voice of People: Public Opinion and Democracy, New Haven, Yale University Press.

Gallaguer, Michael y Paul Mitchells (2009), The Politics of Electoral Systems, Oxford, Oxford University Press.

Goldman, Seth y Diana Mutz (2011), "The Friendly Media Phenomenon: A Cross-National Analysis of CrossCutting Exposure", Political Communication, 28, pp. 42-66.

Gunther, Richard, José R. Montero y Mariano Torcal (2007), "Democracy and Intermediation: Some Attitudinal and Behavioral Dimensions", en Richard Gunther, José Ramón Montero y Hans-Jürgen Puhle (eds.), Democracy, Intermediation and Voting on Four Continents, Nueva York, Oxford University Press.

Habermas, Jünger (1984), The Theory of Communicative Action: Reason and Rationalization of Society, Cambridge, Polity Press.

Huckfeldt, Robert y John Sprague (1995), Citizens, Politics and Social Communication: Information and Influence in an Election Campaign, Nueva York, Cambridge University Press.

Huckfeldt, Robert, Paul E. Johnson y John Sprague (2004), Political Disagreement: The Survival of Diverse Opinions within Communication Networks, Nueva York, Cambridge University Press.

Huckfeldt, Robert, Jeanett Morehouse Mendez y Tracy Osborn (2004), "Disagreement, Ambivalence, 
and Engagement: The Political Consequences of Heterogeneous Networks", Political Psychology, 25, pp. 65-95.

Huckfeldt, Robert, Ken'ichi Ikeda y Franz U. Pappi (2005), "Pattern of Disagreement in Democratic Politics: Comparing Germany, Japan and the United States", American Journal of Political Science, 49, pp. 497-514. Ikeda, Ken'ichi y Robert Huckfeldt (2001), "Political Communication and Disagreement among Citizens in Japan and the United States", Political Behavior, 23, pp. 23-52.

Jackman, Simon y Paul M. Sniderman (2006), “The Limits of

Deliberative Discussion: A Model of Everyday Political Argument", Journal of Politics, 68, pp. 272-283.

Katz, Elihu (1981), "Publicity and Pluralistic Ignorance:

Notes on the Spiral of Silence", en Horst Baler, Hans M. Kepplinger y Kurt Reuman (eds.), Public Opinion and Social Change: For Elisabeth Noelle-Neumann, Weisbaden, Westdeutscher Verlag, pp. 28-38.

Laakson, Markku y Rein Taagapera (1979), "Effective Number of Parties: A Measure with Application to West Europe", Comparative Political Studies, 12, pp. 3-27.

La Due Lake, Ronald y Robert Huckfeldt (1998), "Social Capital, Social Networks, and Political Participation", Political Psychology, 19, pp. 567-584.

Lazarfeld, Paul F., Bernard R. Berelson y Hazel Gaudet (1944), The People's Choice: How the Voter Makes Up His Mind in a Presidential Campaign, Nueva York, Duell, Sloan and Pearce.

Lup, Oana (2010), "The Role of Political Discussion in Developing Democracies: Evidence from Hungary", en Michael R. Wolf, Laura Morales y Ken'ichi Ikeda, eds., Political Discussion in Modern Democracies: A Comparative Perspective, Londres, Routlegde. 
Lupia, Arthur y Matthew D. McCubbins (1998), The Democratic Dilemma: Can Citizens Learn What They Need to Know?, Nueva York, Cambridge University Press.

Luskin, Robert C. y James S. Fishkin (2002), Deliberation and "better citizens", Austin, University of Texas at Austin. Magalhães, Pedro (2007), "Voting and Intermediation: Informational Biases and Electoral Choice in Comparative Perspective", en Richard Gunther, José R. Montero y Hans-Jürgen Puhle (eds.), Democracy, Intermediation and Voting on Four Continents, Nueva York, Oxford University Press.

Marquis, Lionel (2010), "Patterns of Support for the Welfare State: The Role of Media and Interpersonal Communication in Direct Democratic Votes in Switzerland (1996-2004)", en Michael R. Wolf, Laura Morales y Ken'ichi Ikeda (eds., )Political Discussion in Modern Democracies: A Comparative Perspective, Londres, Routlegde.

Morales, Laura (2010), "Getting a Single Message? The Impact of Homogeneous Political Communication Contexts in Spain in Comparative Perspective", en Michael R. Wolf, Laura Morales y Ken'ichi Ikeda (eds.), Political Discussion in Modern Democracies: A Comparative Perspective, Londres, Routlegde.

Moy, Patricia y John Gastil (2006), "Predicting Deliberative Conversation: The Impact of Discussion Networks, Media Use, and Political Cognition", Political Communication, 23, pp. 443-460.

Mutz, Diana C. (1998), Interpersonal Influence: How Perceptions of Mass Collectives Affect Political Attitudes, Nueva York, Cambridge University Press.

-_(2002a), "The Consequences of Cross-Cutting Networks for Political Participation", American Journal of Political Science, 46, pp. 838-855. 
_-(2002b), "Cross-Cutting Social Networks: Testing Democratic Theory in Practice", American Political Science Review, 96, pp. 111-126.

_-_(2006), Hearing the Other Side: Deliberative versus Participatory Democracy, Nueva York, Cambridge University Press.

Mutz, Diana C. y P. S. Martin (2001), “Facilitating Communication across Lines of Political Difference: The Role of Mass Media", American Political Science Review, 95, pp. 97-114.

Mutz, Diana C. y Jeffery Mondak (2006), "The Workplace as a Context for Cross-Cutting Political Discourse", Journal of Politics, 68, pp. 140-155.

Newton, Kenneth (1999), "Mass Media Effects: Mobilization or Media Malaise?", British Journal of Political Science, 29, pp. 577-599.

Niemi, Richard G., Stephen C. Craig y Franco Mattei (1991), "Measuring Internal Political Efficacy in the 1988 National Election Study", American Political Science Review, 85, pp. 1407-1413.

Nir, Lilach (2005), "Ambivalent Social Networks and their Consequences for Participation", International Journal for Public Opinion Research, 17, pp. 422-442.

Norris, Pippa (1999), "Introduction: The Growth of Critical Citizens", en Pippa Norris (ed.), Critical Citizens: Global Support for Democratic Governance, Nueva York, Oxford University Press.

-_(2000), A Virtuous Circle? Political Communication in Post-Industrial Democracies, Nueva York, Cambridge University Press.

_-(2011), Democratic Deficits: Critical Citizens Revisited, Nueva York, Cambridge University Press.

Putnam, Robert (1993), Making Democracy Work: Civic Traditions in Modern Italy, Princeton, Princeton University Press. 
_-(2000), Bowling Alone: The Collapse and Revival of American Community, Nueva York, Simon \& Schuster. Prior, Markus (2007) Post-Broadcast Democracy: How Media Choice Increase Inequality in Political Involvement and Polarize Election, Nueva York, Cambridge University Press.

Richardson, Bradley y Paul A. Beck (2007). “The Flow of Political Information: Personal Discussants, the Media, and Partisans", en Richard Gunther, José R. Montero y Hans-Jünger Puhle (eds.), Democracy, Intermediation and Voting on Four Continents, Nueva York, Oxford University Press.

Rosenberg, Shawn (2007), "Ways of Talking, Types of Democratic Deliberation and the Limits of Participation", paper presented at the Joint Sessions and Workshops of the European Consortium of Political Research, Helsinki, Finland.

Schmitt-Beck, Rüdiger (2003), "Mass Communication, Personal Communication and Vote Choice: The Filter Hypothesis of Media Influence in Comparative Perspective", British Journal of Political Science, 33, pp. 233-259.

Schmitt-Beck, Rüdiger. y Katrin Voltmer (2007), “The Mass Media in Third-Wave Democracies: Gravediggers or Seedsmen of Democratic Consolidation?", en Richard Gunther, José R. Montero y Hans-Jünger Puhle (eds.), Democracy, Intermediation and Voting on Four Continents, Nueva York, Oxford University Press.

Schmitt-Beck, Rüdiger y Christian Mackenrodt (2010), "Social Networks and Mass Media as Mobilizers and Demobilizers: A Study of Turnout at a German Local Election", Electoral Studies, 29, pp. 392-404.

Searing, Donald D., Frederick Solt, Pamela Johnston Conover e Ivor Creew (2007), "Public Discussion in 
the Deliberative System: Does It Make Better Citizens?", British Journal of Political Science, 37, pp. 587-618.

Schuefele, Dietram A., Matthew Nisbet, Dominique Brossard y Erik Nisbet (2004), "Social Structure and Citizenship: Examining the Impacts of Social Settings, Network Heterogeneity, and Informational Variables on Political Participation", Political Communication, 21, pp. 315-338.

Strömbäck, Jesper y Adam Shehata (2010), “Media Malaise or a Virtuous Circle? Exploring the Causal Relationships Between News Media Exposure, Political News Attention and Political Interest", European Journal of Political Research, 49, pp. 575-597.

Toka, Gabor (2010), “The Impact of Everyday Political Talk on Involvement, Knowledge, and Informed Voting", en Michael R. Wolf, Laura Morales y Ken'ichi Ikeda, eds., Political Discussion in Modern Democracies: A Comparative Perspective, Londres, Routlegde.

Torcal, Mariano y José R. Montero (2006), "Political Disaffection in Comparative Perspective", en Mariano Torcal y José R. Montero (eds.), Political Disaffection in Contemporary Democracies: Social Capital, Institutions and Politics, Londres, Routledge.

Ulbig, Stacy G., y Carolyn L. Funk. (1999), "Conflict Avoidance and Political Participation" Political Behavior 21 (3), pp. 265-282.

Van Deth, Jan (1990), “Interest in Politics”, en M. K. Jennings et al. (eds.), Continuities in Political Action. A Longitudinal Study of Political Orientations in Three Western Democracies. Berlín, Walter de Gruyter.

Verba, Sidney, Kay L. Schlozman y Henry Brady (1995), Voice and Equality: Civic Voluntarism in American Politics, Cambridge, Harvard University Press.

Zaller, John (1992), The Nature and Origins of Mass Opinion, Nueva York, Cambridge University Press. 
-_(1996), "The Myth of Massive Media Impact Revived: New Support for a Discredited Idea”, en Diana C. Mutz, Paul M. Sniderman y Richard A. Brody (eds.), Political Persuasion and Attitudinal Change. Michigan, Michigan University Press. 